\title{
The Visually Related Posterior Pretectal Nucleus in the Non-Percomorph Teleost Osteoglossum bicirrhosum Projects to the Hypothalamus: A DiI Study
}

\author{
MARIO F. WULLIMANN, DIETRICH L. MEYER, AND R. GLENN NORTHCUTT \\ Department of Neuroanatomy, University of Göttingen School of Medicine, Göttingen, \\ Germany, and Neurobiology Unit SIO, Department of Neurosciences A-001, University of \\ California at San Diego, La Jolla, California 92093 (R.G.N.)
}

\begin{abstract}
This study was done to elucidate the ancestral (plesiomorphic) condition for visual pathways to the hypothalamus in teleost fishes. Three patterns of pretectal organization can be discerned morphologically and histochemically in teleosts. Their taxonomic distribution suggests that the intermediately complex pattern (seen in most teleost groups) is ancestral to both the elaborate pattern (seen in percomorphs) and the simple pattern (seen in cyprinids). The pretectal nuclei involved can be demonstrated with acetylcholinesterase histochemistry selectively and reliably in different species of teleosts, suggesting that the same-named nuclei are homologous in representatives of the three different patterns.

Whereas there are visual pathways to the hypothalamus in both the elaborate (percomorph) and the simple (cyprinid) patterns, different pretectal and hypothalamic nuclei are involved. Thus visual hypothalamic pathways in these two patterns would not appear to be homologous.

In this study, circuitry within the third, i.e., the intermediately complex, pattern is investigated. It is demonstrated that visual pathways project via the pretectum to the hypothalamus in Osteoglossum bicirrhosum and that they are very similar to the visual pathways in the elaborate pattern. This suggests that the circuitry in the intermediately complex pattern, as represented by Osteoglossum, is plesiomorphic (evolutionarily primitive) and the circuitry in both the simple pattern (seen in cyprinids) and the elaborate pattern (seen in percomorphs) is apomorphic (evolutionarily derived) for teleosts.
\end{abstract}

Key words: diencephalon, fluorescent neuronal tracer, nucleus glomerulosus, ray-finned fishes, vision

Percomorph teleost fishes are characterized by a conspicuous concentrical cellular aggregate in the diencephalon, the nucleus glomerulosus (Fig. 1B; nucleus rotundus hypothalami of Fritsch, 1878; Ito and Kishida, '75; see Discussion: history of pretectal nomenclature). It receives higher order visual afferents from two pretectal nuclei, the intermediate superficial pretectal nucleus (SPn) and the nucleus corticalis (Sakamoto and Ito, '82; Murakami et al., '86; Striedter and Northcutt, '86, '89; Wullimann and Northcutt, ' 86 ), and its only known efferent target is the hypothalamic inferior lobe (Sakamoto and Ito, '82, see Fig. 10B). The caudal portion of nucleus glomerulosus is embedded in the preglomerular cell aggregate (Fig. 1B) and has sometimes been confused with it (see Braford and Northcutt, '83; Northcutt and Wullimann, '88; Wullimann, '88, and Discussion: history of pretectal nomenclature). The anterior part of nucleus glomerulosus extends far rostral and lies immediately caudal to the intermediate SPn (Northcutt and Wullimann, '88; Wullimann and Meyer, '90; Fig. 1B; see also Fig. 10B).

In contrast to percomorphs, most non-percomorph teleosts lack a nucleus glomerulosus. Instead, they have a cytoarchitectonically simpler posterior pretectal nucleus (Figs. 1A, 2-4; nucleus anterior thalami of Franz, '12; see Discussion: history of pretectal nomenclature). This pretectal nucleus may be of variable size, but it is always in a position comparable to that of the intermediate SPn or the anterior portion of nucleus glomerulosus in percomorphs. The posterior pretectal nucleus, however, does not extend

\footnotetext{
Accepted June 26, 1991
}

Address reprint requests to Dr. M.F. Wullimann, Brain Research Institute, University of Bremen, FB 2, Postfach 3304 40, D-2800 Bremen 33, Germany. 
so far ventrally as to be embedded in the preglomerular cell masses, as does nucleus glomerulosus (compare A and B in Fig. 1). Although the posterior pretectal nucleus has been observed in all four major groups of teleosts (Northcutt and Wullimann, '88; Wullimann and Meyer, '90), until recently no hodological or histochemical information was available to support a possible homology with nucleus glomerulosus or the intermediate $\mathrm{SPn}$ in percomorphs.

Recently it was demonstrated that at least three different patterns of pretectal organization can be recognized in teleosts (Wullimann and Meyer, '90): an intermediately complex pattern is present in most non-percomorph teleosts; an elaborate pattern is seen in atherinomorphs and percomorphs; and a simple pattern is found in cyprinids. The general morphology of these patterns is summarized schematically in Figure 1: the posterior pretectal nucleus and nucleus glomerulosus form part of the intermediately complex pattern and elaborate pattern, respectively. The posterior pretectal nucleus lies directly caudomedial to the superficial pretectum, dorsal to the preglomerular cell masses (Fig. 1A). Nucleus corticalis is also present in the intermediately complex pattern. In contrast, nucleus glomerulosus in the elaborate pattern extends ventrally into the preglomerular region (Fig. 1B). Rostrolaterally, it lies immediately caudal to the intermediate SPn, a division of the superficial pretectum not seen in the other two patterns. Nucleus corticalis is also present in the elaborate pattern. In the simple pattern, the posterior pretectal nucleus is a small nucleus located directly caudal to the superficial pretectum (Fig. 1C), and the nucleus corticalis is absent.

The elaborate pattern is found only in derived teleosts, such as percomorphs, whereas the intermediately complex pattern is present in at least some species of most other teleost groups, such as osteoglossomorphs, clupeomorphs, esocids, and salmonids, and the simple pattern is seen in some cyprinid species (Wullimann and Meyer, '90). An outgroup analysis of the taxonomic distribution of pretectal patterns indicates that the intermediately complex pattern is plesiomorphic (evolutionarily primitive) and that both the simple and elaborate patterns represent apomorphic (evolutionarily derived) conditions (Wullimann and Meyer, '90).

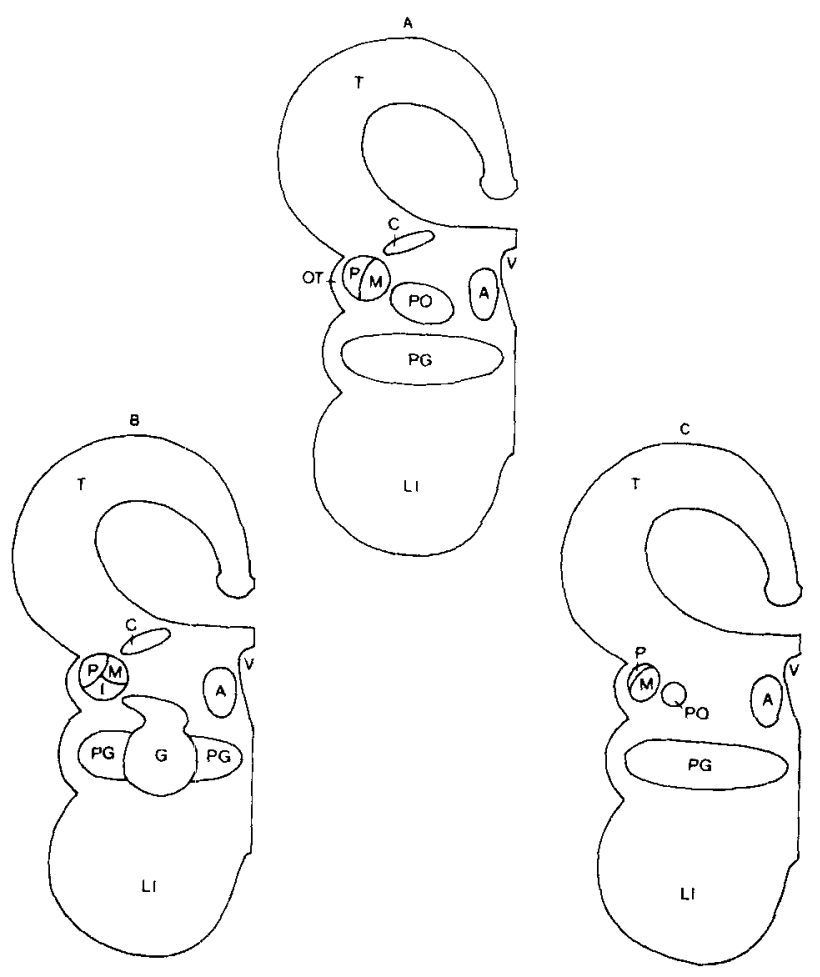

Fig. 1. Schematic drawings of cross sections through the diencephalon and mesencephalon of a teleost fish showing the general topology of the three recognized pretectal patterns. A. Intermediately complex pretectal pattern exhibited by most ancestral teleost groups, e.g., Osteoglossum bicirrhosum. B. Elaborate pretectal pattern observed in derived teleosts, e.g., percomorphs. C. Simple pretectal pattern present in cyprinids. See abbreviations list.

In species chosen very selectively, Wullimann and Meyer ('89, '90) described the normal anatomy in all three pretectal patterns in detail and further characterized these patterns with acetylcholinesterase histochemistry. These histochemical findings support the hypothesis that the
Abbreviations

$\begin{array}{ll}\text { A } & \text { nucleus anterior thalami } \\ \text { AP } & \text { nucleus pretectalis accessorius } \\ \text { BS } & \text { brainstem } \\ \text { BO } & \text { bulbus olfactorius } \\ \text { C } & \text { nucleus corticalis } \\ \text { Ce } & \text { corpus cerebelli } \\ \text { CH } & \text { cornmissura horizontalis } \\ \text { CM } & \text { corpus mammillare } \\ \text { CP } & \text { nucleus pretectalis centralis } \\ \text { CPo } & \text { commissura posterior } \\ \text { CS } & \text { commissura supraoptica } \\ \text { Dl } & \text { nucleus diffusus lobi inferiores pars lateralis } \\ \text { Dm } & \text { nucleus diffusus lobi inferiores pars medialis } \\ \text { FR } & \text { fasciculus retroflexus } \\ \text { G } & \text { nucleus glomerulosus } \\ \text { H } & \text { tuberal hypothalamus } \\ \text { Ha } & \text { habenula } \\ \text { Hv } & \text { ventral periventricular hypothalamus } \\ \text { I } & \text { nucleus pretectalis superficialis pars intermedius } \\ \text { IR } & \text { inferior raphe } \\ \text { L } & \text { lateral forebrain bundle } \\ \text { LI } & \text { lobus inferior hypothalami } \\ \text { M } & \text { nucleus pretectalis superficialis pars magnocellularis } \\ \text { MO } & \text { medulla oblongata } \\ \text { NI } & \text { nucleus isthmi } \\ & \end{array}$

$\begin{array}{ll}\text { NT } & \text { nucleus pervi trochlearis } \\ \text { ON } & \text { nervis opticus } \\ \text { OT } & \text { tractus opticus } \\ \text { P } & \text { nucleus pretectalis superficialis pars parvocellularis } \\ \text { PG } & \text { nucleus preglomerulosus } \\ \text { PL } & \text { nucleus periventricularis recessus lateralis } \\ \text { PO } & \text { nucleus pretectalis posterior } \\ \text { POc } & \text { nucleus pretectalis posterior pars caudomedialis } \\ \text { POr } & \text { nucleus pretectalis posterior pars rostrolateralis } \\ \text { PP } & \text { nucleus preopticus parvocellularis } \\ \text { PPd } & \text { nucleus pretectalis periventricularis pars dorsalis } \\ \text { PPv } & \text { nucleus pretectalis periventricularis pars ventralis } \\ \text { R } & \text { retina } \\ \text { SPn } & \text { superficial pretectal nucleus (used in text only) } \\ \text { T } & \text { tectum opticum } \\ \text { Te } & \text { tegmentum } \\ \text { Tel } & \text { telencephalon } \\ \text { TL } & \text { torus longitudinalis } \\ \text { TS } & \text { torus semicircularis } \\ \text { V } & 3^{\text {di brain ventricle }} \\ \text { Va } & \text { valvula cerebelli } \\ \text { VL } & \text { nucleus ventrolateralis thalami } \\ \text { VM } & \text { nucleus ventromedialis thalami } \\ \text { VOT } & \text { ventrolateral optic tract }\end{array}$




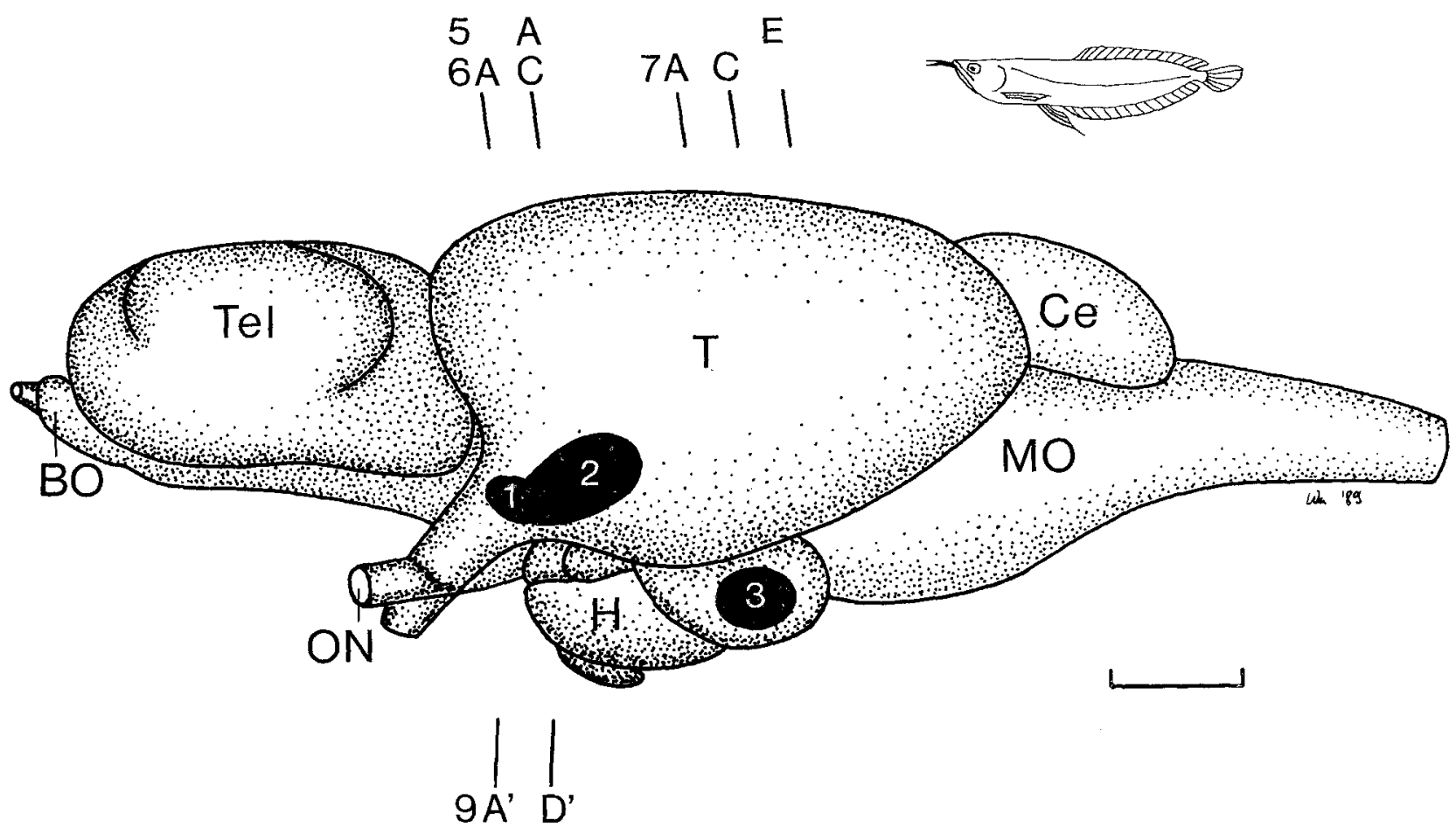

Fig. 2. Lateral view of the brain of Osteoglossum bicirrhosum. The three sites where DiI was applied are marked: (1) parvicellular superficial pretectal nucleus, (2) posterior pretectal nucleus, (3) inferior lobe.
Levels of several cross sections from Figures 5 to 9 are indicated. Sketch in upper right corner shows the body outline of Osteoglossum. See abbreviations list. Bar $=1 \mathrm{~mm}$ same-named nuclei in the three patterns are homologous. Although the circuitry in the elaborate pattern forms part of the visual pathways to the hypothalamus (see below), the circuitry in the intermediately complex pattern is unknown. Osteoglossum was thus chosen for histochemical investigation (Wullimann and Meyer, '90), because it shows the intermediately complex pretectal pattern. The goal of the present study is to establish whether or not there are connections in Osteoglossum that form visual pathways to the hypothalamus, similar to those seen in the elaborate percomorph pretectal pattern.

Combined with the previous histochemical evidence, the present finding that the caudomedial portion of the posterior pretectal nucleus has connections very similar to those of nucleus glomerulosus strongly supports the hypothesis that the caudomedial portion of the posterior pretectal nucleus and nucleus glomerulosus are homologous.

The neuroanatomical nomenclature used is that of Braford and Northcutt ('83), modified slightly by Northcutt and Wullimann ('88) and Wullimann and Meyer ('90). An extensive review of the historical development of this nomenclature is also provided (Discussion: history of pretectal nomenclature). Taxonomic nomenclature is according to Lauder and Liem ('83). A preliminary report was published previously (Wullimann and Northcutt, '89).

\section{MATERIALS AND METHODS}

Arawanas (Osteoglossum bicirrhosum, 6-12 cm standard length) were obtained from a local dealer and housed in group tanks at $25^{\circ} \mathrm{C}$ before the experiments.

The availability of the carbocyanine dye $\mathrm{DiI}$ as a new tool for tracing neuronal connections greatly facilitated this study. As DiI can be used on fixed tissue (Godement et al.,
'87), the tracer can be applied to brains already removed from their crania. This allows access to portions of the central nervous system, such as the inferior lobes, not readily accessible in living specimens.

\section{Dil experiments}

The animals were deeply anesthetized in a dilute solution of tricaine methanesulfonate (Sigma) before being transcardially perfused with 1\% Heparin (Braun, Melsungen), in either $0.1 \mathrm{M}$ phosphate buffer (pH: 7.4) or teleost Ringers solution, followed by $4 \%$ paraformaldehyde in $0.1 \mathrm{M}$ phosphate buffer. The brains were removed from the skulls and kept in $4 \%$ paraformaldehyde at $4^{\circ} \mathrm{C}$ for 1 to 156 days. Thereafter, minute crystals of the carbocyanine dye $1,1^{\prime}$ dioctadecyl-3,3,3',3'-tetramethylindo-carbocyanine perchlorate [DiI-C-18 (3); Molecular Probes, Eugene, OR] were injected into specific brain areas. Small slits were cut in the appropriate location with a scalpel, and DiI crystals were pushed into these slits with a needle or fine forceps. Liquid 4\% agar-agar (Merck, Darmstadt) was then poured over the application site to ensure that the crystals remained in place. The DiI was applied to three specific sites (see Fig. 2): (1) the parvicellular SPn (3 cases), (2) the posterior pretectal nucleus ( 6 cases), and (3) the inferior lobe ( 3 cases).

The brains were incubated at $40^{\circ} \mathrm{C}$ in $4 \%$ paraformaldehyde in a light-tight container for various time periods: 11, 15 , and 55 days for the parvicellular SPn, 10-30 days for the posterior pretectal nucleus, and 10,13 , and 60 days for the inferior lobe. After incubation, the brains were dried, and the agar was removed from the site of the DiI application. The tissue was then glued to a base and covered with fluid agar before being cut on a vibratome at $50 \mu \mathrm{m}$. Some brains were dipped in a gelatin (10\%)-sucrose (30\%) medium $\left(40^{\circ} \mathrm{C}\right)$ for at least 30 minutes, embedded in this 

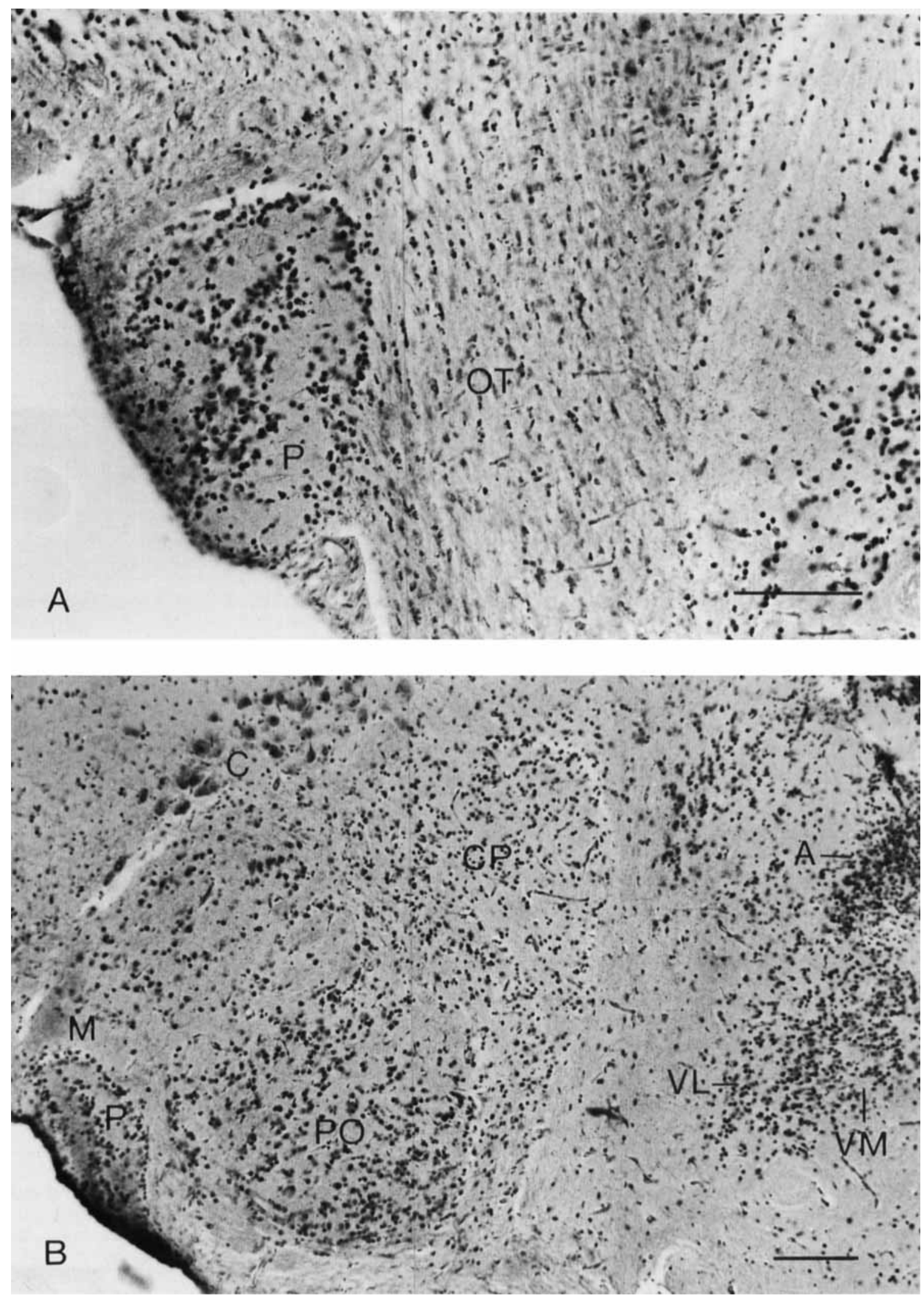

Fig. 3. Photomicrographs of Bodian-stained cross sections showing the normal anatomy of the anterior part of the pretectum and dorsal thalamus in Osteoglossum from rostral (A) to caudal (B). Bars $=0.1 \mathrm{~mm}$. Lateral is to the left. See abbreviations list. 

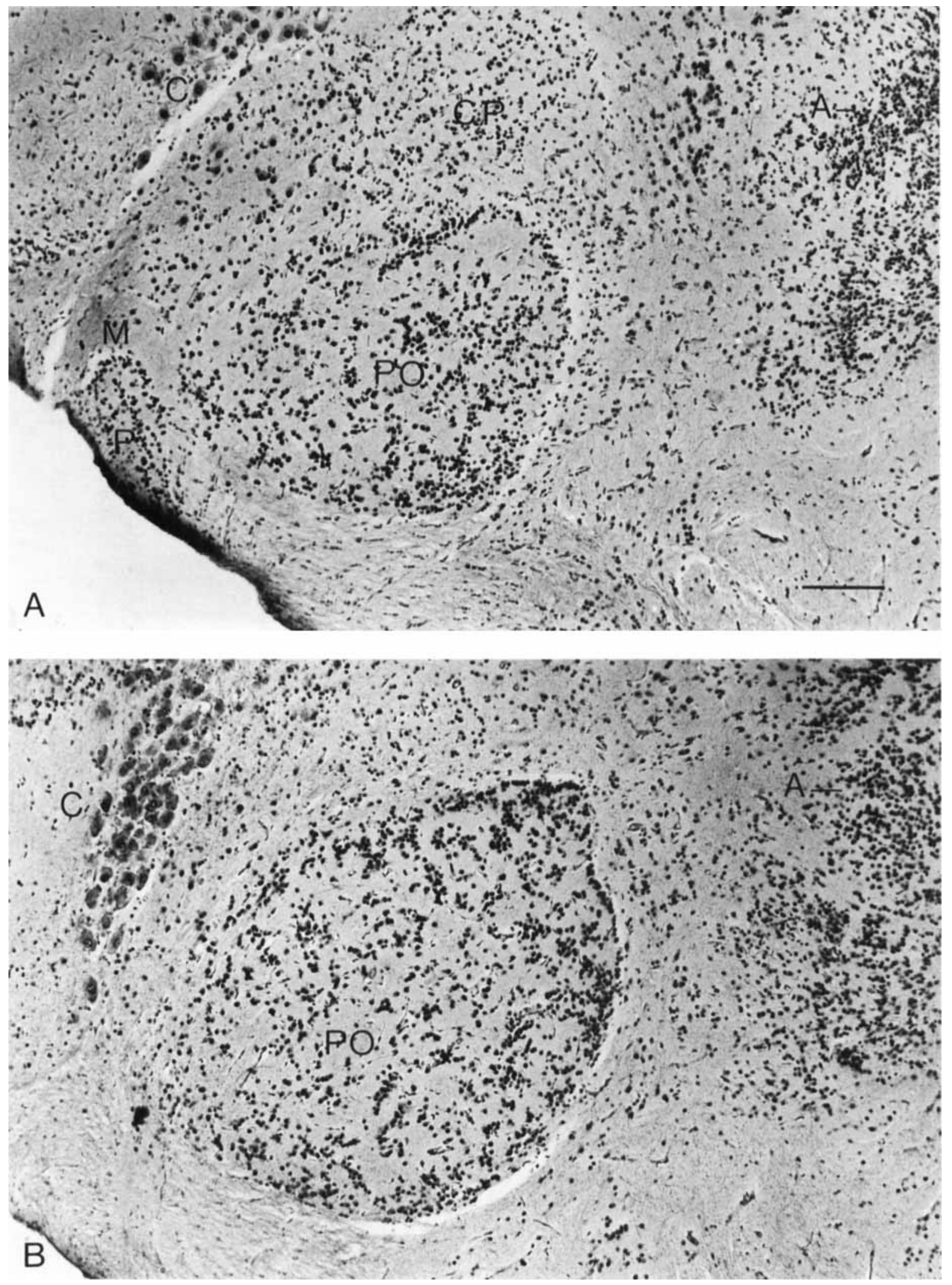

Fig. 4. Photomicrographs of Bodian-stained cross sections showing the normal anatomy of the posterior part of the pretectum and dorsal thalamus in Osteoglossum from rostral (A) to caudal (B). Bar $=0.1 \mathrm{~mm}$. Lateral is to the left. See abbreviations list. 

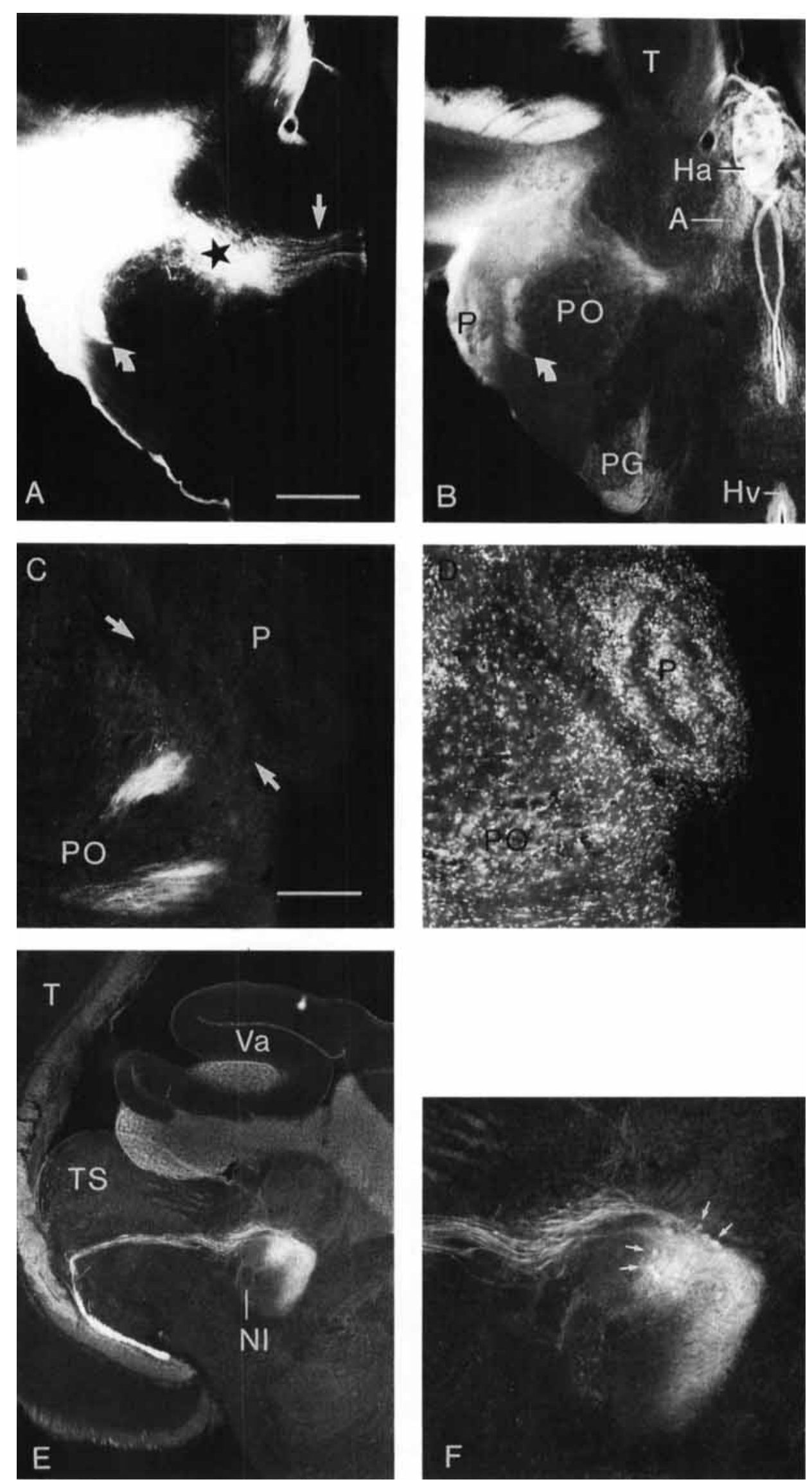

Figure 5 
medium, and stored at $4^{\circ} \mathrm{C}$ overnight. The block containing the embedded brain was then fixed in $4 \%$ paraformaldehyde overnight prior to sectioning. The sections were collected in $0.1 \mathrm{M}$ phosphate buffer. Many sections were dipped for a few seconds in a fluorescent counterstain, rendering a Nissl-stainlike appearance of the nervous tissue (as described by Quinn and Weber, '88). Thereafter the sections were rinsed in phosphate buffer and mounted with Fluoromount (Fisher Biotech).

\section{Normal anatomy}

A series of silver-stained sections of a brain of Osteoglossum was available for comparison with the DiI material. Details on the histological preparation of this brain are presented elsewhere (Wullimann and Meyer, '90).

\section{Photography}

A rhodamine-type filter (530-560 nm) and a FITC-type filter $(450-490 \mathrm{~nm})$ were used to visualize the DiI and counterstain, respectively. Photomicrographs were taken with Kodak plus-X-pan 125 ASA film. Some labeled structures could not be photographed within one frame, in which case composition photographs were made (see Fig. 9).

\section{RESULTS}

We first describe the normal anatomy of the pretectum in Osteoglossum and then report the connections of the parvicellular SPn, the posterior pretectal nucleus, and the inferior lobe in Osteoglossum indicated for the three sets of experiments. Finally, we summarize the visual circuits to the hypothalamus in Osteoglossum.

\section{Normal anatomy of the pretectum}

This section briefly describes the normal anatomy of the pretectum in Osteoglossum. For a more detailed description of the anatomy comprising all three pretectal patterns, see Wullimann and Meyer ('90). Most rostrally, the parvicellular SPn lies embedded in the optic tract (Fig. 3A); more caudally and dorsomedially, a small magnocellular SPn can be observed (Figs. 3B, 4A) The posterior pretectal nucleus lies ventral to these superficial pretectal nuclei and extends farther caudally than the latter (Figs. 3B, 4). The huge

Fig. 5. Photomicrographs of cross sections showing anterograde and retrograde transport after DiI application to the parvicellular superficial pretectal nucleus. A. Section is slightly caudal to center of the DiI application site. Note the projection to the rostrolateral portion of the posterior pretectal nucleus (curved arrow) and the absence of label in the rest of the nucleus. Also labeled are somata of radial glial cells, located in the ependyma of the third ventricle and extending processes (straight arrow) toward the meninges. Because the Dil application site is embedded in the optic tract, many optic fibers and their terminal fields (e.g., in the central pretectal nucleus, see asterix) are labeled as well. B. Same section as shown in (A) but counterstained, rendering a Nissllike appearance. Note the bright fluorescence in the rostrolateral portion of the posterior pretectal nucleus (see Discussion). C. Contralateral terminal field in the rostrolateral portion of the posterior pretectal nucleus. Arrows indicate boundary between the parvicellular portion of the superficial pretectal nucleus and the posterior pretectal nucleus. D. Same section as in $\mathrm{C}$ but counterstained, demonstrating the position of terminal fields within the posterior pretectal nucleus. E. Retrogradely labeled isthmo-pretectal tract and cells in nucleus isthmi. F. Magnification of retrogradely labeled cells (arrows) in nucleus isthmi. See abbreviations list. Bar in $\mathrm{A}=0.25 \mathrm{~mm}$ and applies also to $B$ and $E$; bar in $C=0.1 \mathrm{~mm}$ and applies also to $\mathrm{D}$ and $F$. Lateral is to the left in $A, B, E$, and F; to the right in $C$ and $D$. neurons of nucleus corticalis are located dorsal to the superficial pretectum (Figs. 3B, 4). The central pretectal nucleus is situated between the nucleus corticalis and the posterior pretectal nucleus (Figs. 3B, 4A).

\section{Connections of the parvicellular superficial pretectal nucleus}

After unilateral application of DiI to the parvicellular SPn (see Fig. 2), heavy labeling was observed, bilaterally, in a small rostrolateral portion of the posterior pretectal nucleus, although the major caudomedial portion was free of label (Fig. 5A,B). This terminal field was somewhat difficult to define ipsilaterally for three reasons: (1) the terminal field was very close to the DiI application site, and it was therefore difficult to distinguish one from the other, (2) as the parvicellular SPn is embedded in the optic tract, retinofugal fibers and their terminal fields were also labeled [e.g., as in the central pretectal nucleus; asterisk in Fig. $5 \mathrm{~A}]$; and (3) radial glia cells in the ependyma of the third ventricle also accumulated tracer via their peripheral processes (straight arrow in Fig. 5A), which extend toward the DiI application site on the brain's surface, thus further obscuring the ipsilateral terminal field.

There is no doubt, however, that the parvicellular SPn projects bilaterally to the rostrolateral portion of the posterior pretectal nucleus for two reasons: First, when a section showing the ipsilateral terminal field of this projection is photographed for the counterstain, it is obvious that the fluorescence in the lateral portion of the ipsilateral posterior pretectal nucleus is brighter than that of the immediate environment (Fig. 5B, curved arrow). As the excitation spectrum of Dil is very broad (Honig and Hume, '89), a less bright, gold fluorescence is also produced when the FITC filter is used to visualize the counterstain. This feature of DiI can be advantageous for visualizing loci of higher DiI density (e.g., terminal fields) in regions of brain tissue with a high background level of the dye (e.g., close to an application site). Second, and more importantly, labeled fibers cross the supraoptic commissure and form two distinct terminal fields in the rostrolateral portion of the contralateral posterior pretectal nucleus (Fig. 5C,D). The formation of two different terminal fields may result from the possible application of two minute crystals of DiI, or, it may indicate two maps of the projection from the superficial pretectal nucleus to the posterior pretectal nucleus.

In addition, the ipsilateral isthmo-pretectal tract and its neurons of origin in nucleus isthmi were labeled (Fig. $5 \mathrm{E}, \mathrm{F}$ ), as were cells in the optic tectum. The latter are at the boundary between the periventricular grey and the deep white zones of the tectum, in a position similar to that of the deep pyriform neurons described in Lepomis (Striedter and Northcutt, '89). Furthermore, labeled fibers descend ipsilaterally through the dorsomedial tegmentum and arborize in the vicinity of the nucleus of the medial longitudinal fascicle. A second descending tract of labeled fibers runs ventromedially in the ipsilateral tegmentum, eventually enters the brain stem, and reaches the vicinity of the inferior raphe. Neither tract, however, has been observed to form a distinct terminal field.

\section{Connections of the posterior pretectal nucleus}

After unilateral application of DiI to the main caudomedial portion of the posterior pretectal nucleus (see Fig. 2), most neurons in nucleus corticalis and some neurons in the parvicellular SPn were labeled ipsilaterally (Fig. 6A-D; see also Fig. 8A,B,D). Some fibers that cross in the posterior 

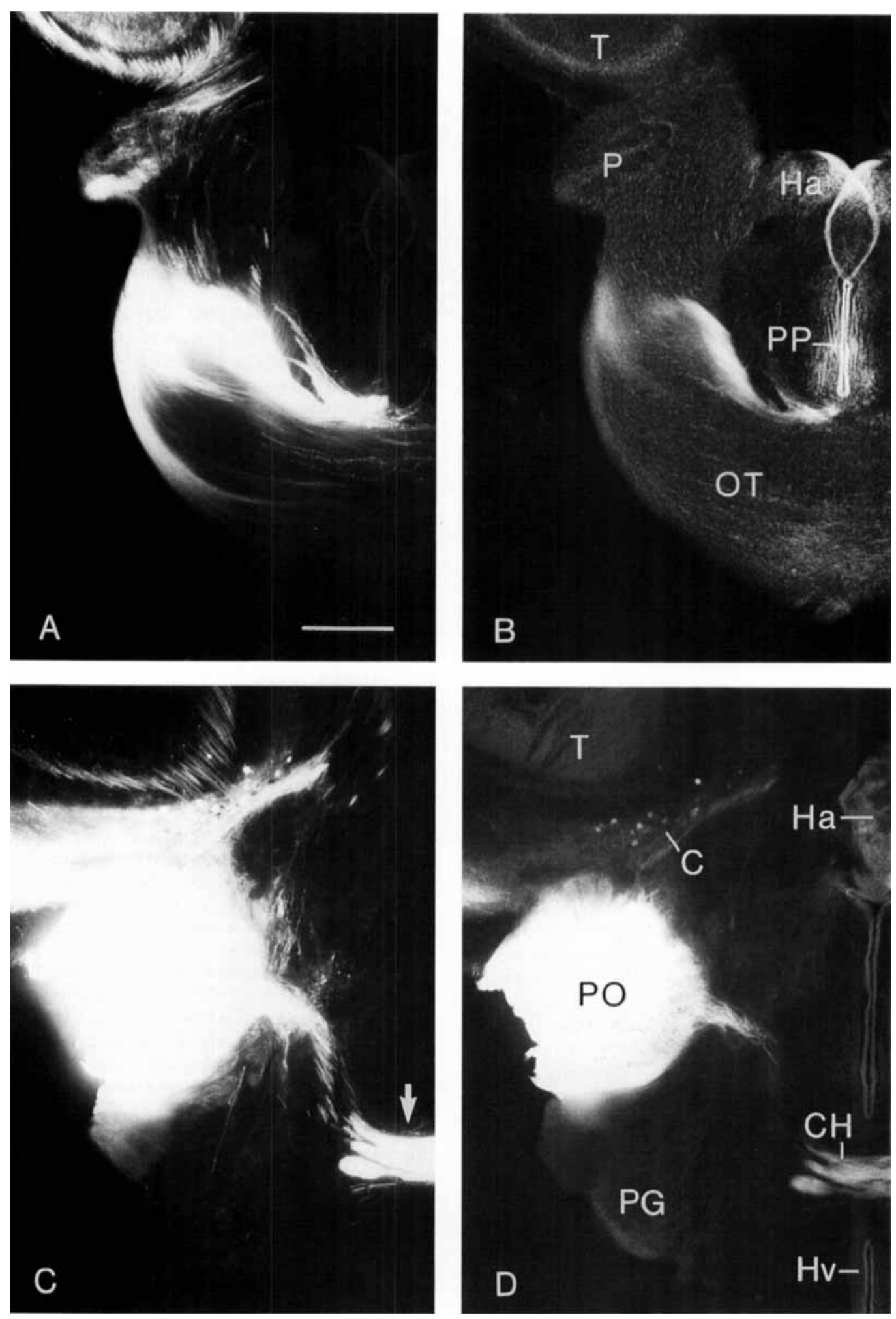

Fig. 6. Photomicrographs of cross sections from rostral (A/B) to caudal $(C / D)$ showing anterograde and retrograde transport after a Dil application covering the posterior pretectal nucleus. A. Filled cells in the parvicellular superficial pretectal nucleus. See text for explanation of anterogradely labeled fibers and terminals in this section. B. Identical section as in A but counterstained, demonstrating the normal

histology. C. DiI application site and retrogradely labeled cells in nucleus corticalis. Arrow points to labeled tectofugal fibers, which cross in the horizontal commissure. D. Identical section as in $\mathrm{C}$ but counterstained, demonstrating the normal histology. See abbreviations list. Bar in $\mathrm{A}=0.25 \mathrm{~mm}$. Lateral is to the left. 

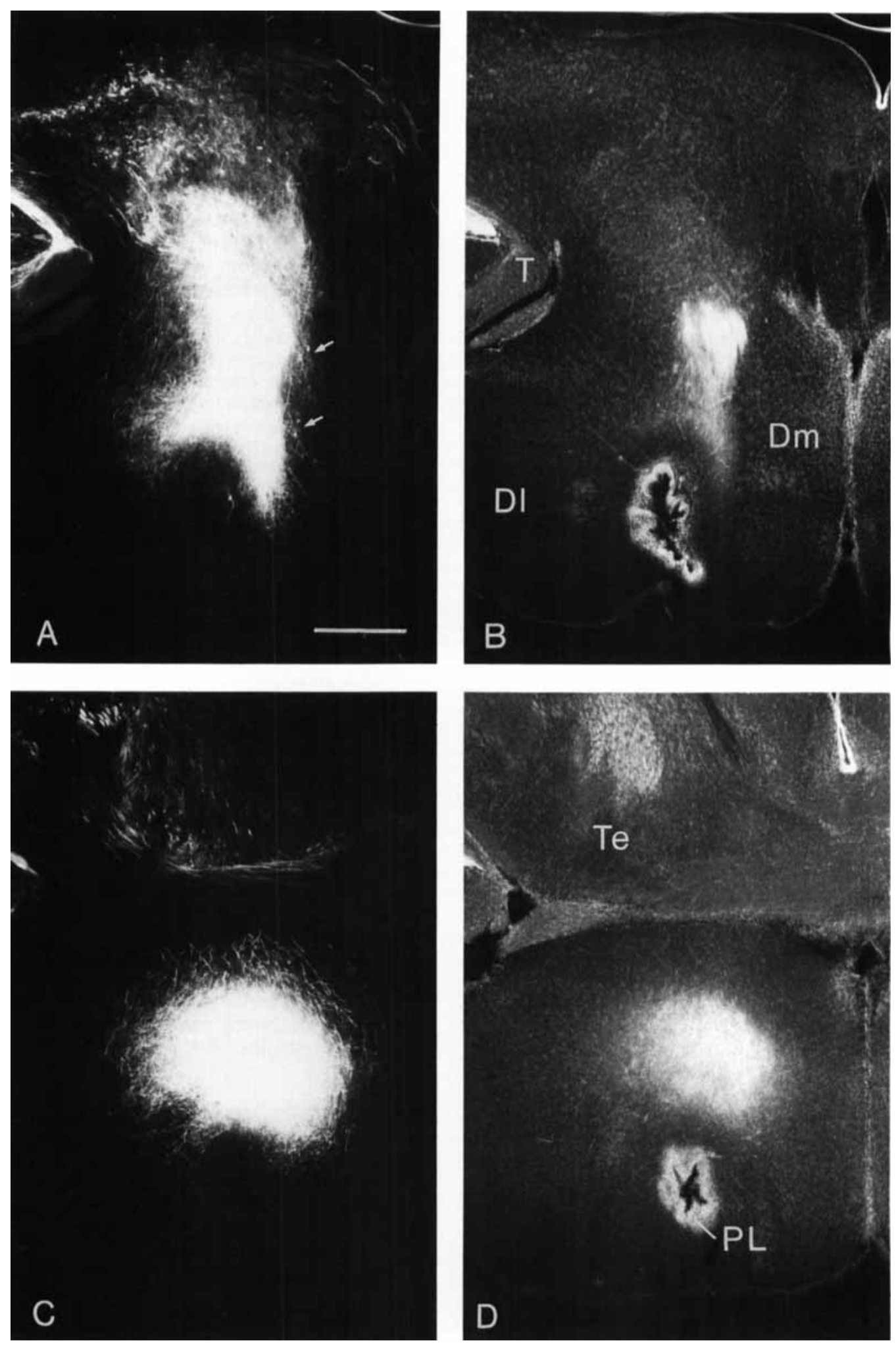

Fig. 7. Photomicrographs of cross sections from rostral $(A / B)$ to caudal (C/D) showing anterograde and retrograde transport after a DiI application covering the posterior pretectal nucleus. A. Major efferent tract and terminal field in the inferior lobe of the hypothalamus. arrows: retrogradely labeled neurons. B. Identical section as in A but counterstained, demonstrating the normal histology. Note that terminals in A do not cover the periventricular nucleus of the inferior lobe.

Even in the counterstained section, the DiI fluorescence is sufficiently bright to mask the central nucleus of the inferior lobe, which is the major efferent target of the posterior pretectal nucleus. C. Terminal field located more caudally in the inferior lobe. D. Identical section as shown in $\mathrm{C}$ but counterstained, demonstrating the normal histology. See abbreviations list. Bar in $A=0.25 \mathrm{~mm}$. Lateral is to the left. 
commissure and their neurons of origin in the contralateral nucleus corticalis were also labeled. In addition, many fibers of passage (e.g., retinofugal fibers terminating in the optic tectum or tectofugal fibers-arrow in Fig. 6Ccrossing in the horizontal commissure) were labeled by the DiI applications to the posterior pretectal nucleus.

A massive descending tract was observed to exit the posterior pretectal nucleus after application of DiI. The tract courses through the preglomerular area and enters the dorsal portion of the ipsilateral inferior lobe. Here, it terminates mostly within the central nucleus but also on the medial and lateral edges of the lateral and medial diffuse nuclei, respectively (Fig. 7A-D). The periventricular nucleus of the inferior lobe remained free of label. A few neurons were retrogradely labeled in the ipsilateral inferior lobe (arrows in Figs. 7A, 8C). They may contribute to the dense fiber net labeled in the posterior pretectal nucleus after DiI applications to the inferior lobe. A dense terminal field can be observed in the rostrolateral portion of the contralateral posterior pretectal nucleus. We interpret this as the terminal field of axons originating in the contralateral parvicellular SPn. Efferent fibers of this nucleus may have been interrupted by DiI applications to the posterior pretectal nucleus (Fig. 8E,F; compare to Fig. 5C,D).

\section{Connections of the inferior lobe}

A detailed description of the connections of the inferior lobe in Osteglossum is the subject of a separate study (see also Wullimann and Northcutt, '90). For purposes of the present study, however, it is critical to establish that the posterior pretectal nucleus in Osteoglossum projects to the inferior lobe. After unilateral application of DiI to the inferior lobe (see Fig. 2), we found most cell bodies and their dendrites retrogradely labeled throughout the entire rostrocaudal extent of the ipsilateral posterior pretectal nucleus (Fig. 9).

When DiI was applied to the ventral inferior lobe, only a few neurons were retrogradely labeled in the posterior pretectal nucleus. This is consistent with the results of DiI applications to the posterior pretectal nucleus, which show that its projection terminates in the dorsal portion of the inferior lobe (see preceding section). Applications of DiI to the ventral inferior lobe revealed widespread dendritic arborizations (Fig. 9E) of the isolated labeled cells in the posterior pretectal nucleus. This partly explains the high density of labeled fibers in the nucleus. When DiI is applied to the inferior lobe more dorsally, however, some labeled fibers in the posterior pretectal nucleus may represent afferent projections from the inferior lobe (see preceding section).

A few retrogradely labeled cells were found in the ipsilateral suprachiasmatic nucleus, and more cells were observed in the ipsilateral secondary gustatory nucleus. Labeled cells were also present in a tegmental band of large neurons, lying ventral to the torus semicirularis, and more ventrocaudally in the tegmentum within the lateral mesencephalic reticular formation.

Many fibers in the lateral forebrain bundle were also heavily labeled. In cases with short incubation times (11 and 13 days), fluorescence in these fiber bundles faded out at the diencephalo-telencephalic junction. In the long term case ( 60 days), the fibers could be followed rostrally to the central zone of the area dorsalis telencephali, where they arborize. No retrogradely labeled cells were observed in the telencephalon.
A descending tract was labeled in the inferior lobe cases. It exits the inferior lobe caudally, enters the ventral tegmentum, and courses caudally toward the brain stem, continually issuing terminal branches before fading out.

\section{Summary}

The three experiments performed in Osteoglossum demonstrate conclusively that the rostrolateral portion of the posterior pretectal nucleus receives bilateral input from the parvicellular superficial pretectal nucleus and that the main caudomedial part of the posterior pretectal nucleus, at least, receives bilateral input from nucleus corticalis. Furthermore, the experiments show that the posterior pretectal nucleus, in turn, projects heavily to the ipsilateral inferior lobe. Finally, the parvicellular superficial pretectal nucleus in Osteoglossum receives direct retinofugal input (M.F. Wullimann and D.L. Meyer, unpublished observations on horseradish peroxidase material). This study, therefore, establishes that visual pathways to the hypothalamus (Figs. 10A, 11A) do exist in Osteoglossum and are similar to those described in percomorph teleosts (Figs. 10B, 11B).

\section{DISCUSSION}

We first discuss some methodological aspects of DiI as a neuronal tracer, then survey the present knowledge of visual pathways to the hypothalamus in teleost fishes. This is followed by a comparison of these pathways in teleosts and other vertebrates, a history of pretectal nomenclature in teleosts, and, finally, our conclusions.

\section{DiI methodology}

Transneuronal transport of DiI reportedly occurs to a limited extent (Godement et al., '87; Honig and Hume, '89). We evaluated the likelihood of this phenomenon in three different ways.

1. All connections forming the visual pathways to the hypothalamus in Osteoglossum have been demonstrated both anterogradely and retrogradely, with the sole exception of the projection from nucleus corticalis to the posterior pretectal nucleus. This was established only retrogradely. When horseradish peroxidase is used as a neuronal tracer, weakly labeled neurons are sometimes visualized retrogradely, although axons between these neurons and the injection site are not labeled (personal observation). In

Fig. 8. Photomicrographs of cross sections showing details of anterograde and retrograde transport after DiI application covering the posterior pretectal nucleus. A. Magnified detail of Figure 6 A shows cells (arrows) in the parvicellular superficial pretectal nucleus. Spherical terminal fields represent afferent projection from nucleus isthmi (see also Striedter and Northcutt, '89). B. Magnified detail of Figure 6C shows retrogradely filled cells (arrows) in nucleus corticalis. C. Magnified detail of Figure $7 \AA$ shows massive terminal field on the central nucleus and some retrogradely filled cells (arrows) in the diffuse nucleus of the inferior lobe. D. Identical section as in B but counterstained. The broad excitation spectrum of DiI allows even more filled cells to be recognized (arrows point to the same nucleus corticalis cells as in (B); see text). E. Terminal field in the posterior pretectal nucleus, probably a projection from the contralateral parvicellular superficial pretectal nucleus, after injection of the contralateral posterior pretectal nucleus (compare to Figure 5C,D and text). F. Identical section as shown in $\mathrm{E}$ but counterstained, demonstrating the position of the terminal field. Abbreviations: see list. $\mathrm{Bar}$ in $\mathrm{A}=0.1 \mathrm{~mm}$; also applies to $\mathrm{B}-\mathrm{F}$. Lateral is to the left in A-D, to the right in $\mathrm{E}$ and $\mathrm{F}$. 

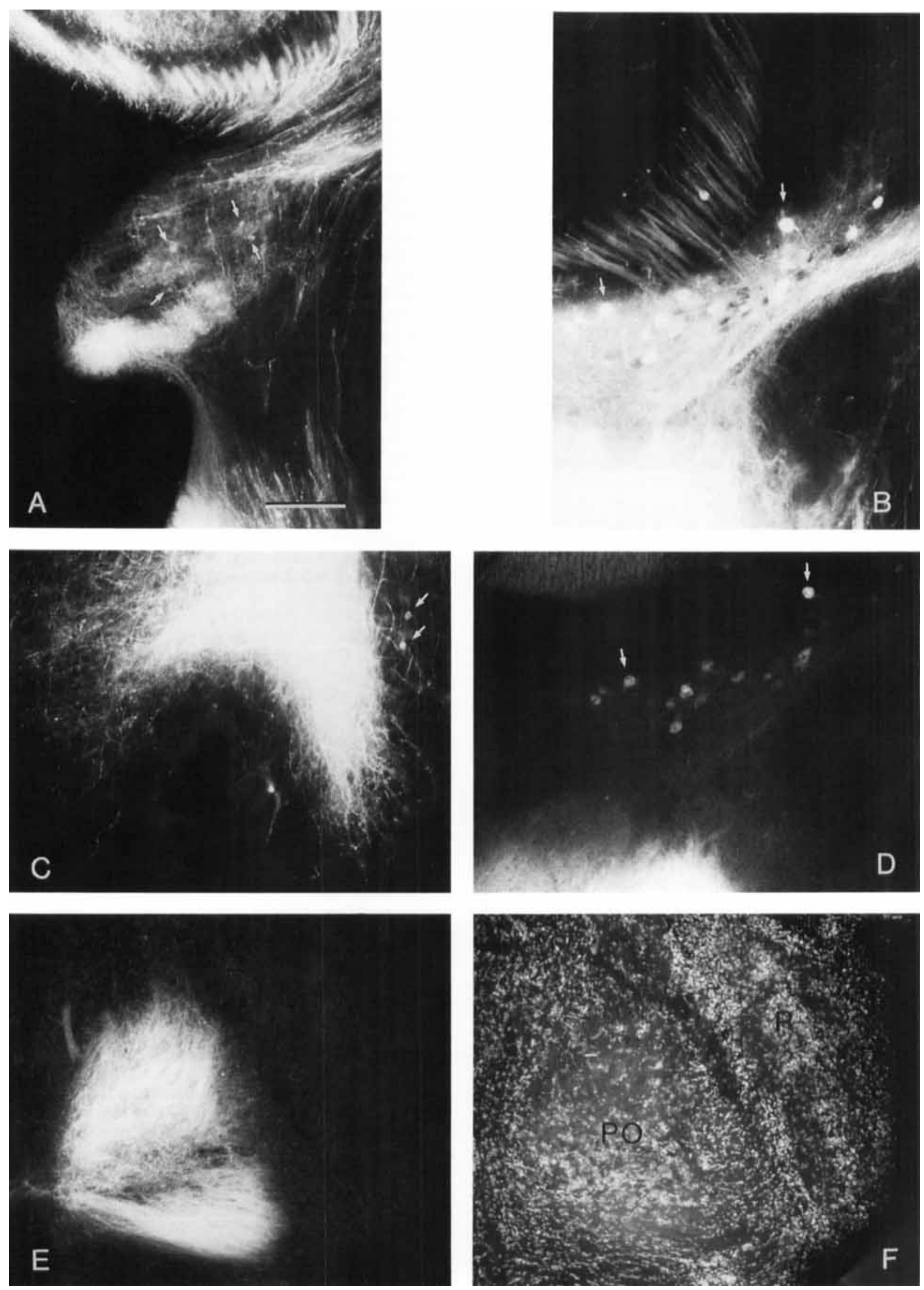
DiI preparations, however, labeled tracts are continuous from the application site to their origin or termination. This is true, and consistent, even in cases of weakly labeled connections (see Fig. 5E,F). In the connections we have described, there were no labeled cell groups between the DiI application site and the labeled cells or terminals, as would be expected if these were cases of transneuronal labeling (see example below). We thus conclude that the labeled projections described in this study (except for the example below) represent true, first-order connections.

2. All three sets of experiments were performed with both short and long incubation times. In one inferior lobe case, we found some labeled neurons in nucleus corticalis, but this occurred only after long-term incubation, and the label was considerably less intense than that in the posterior pretectal nucleus. Therefore, it is our interpretation that these corticalis neurons have been transneuronally labeled via synapses in the posterior pretectal nucleus. There were no qualitative differences between short-term and longterm incubation times in any other cases.

3 . The connections of the parvicellular SPn have been established with the use of horseradish peroxidase in two other teleost species (Murakami et al., '86; Striedter and Northcutt, '89). Both of these studies reported connections very similar to those in Osteoglossum (see below).

These observations are consistent with those of other researchers (Godement et al., '87; Honig and Hume, '89), and they indicate that transneuronal transport is not a major problem in the use of the fluorescent dye DiI as a neuronal tracer in fixed tissue.

\section{Visual pathways to the hypothalamus in teleosts}

It was recently argued that at least three morphological patterns of pretectal organization exist in teleosts (Wullimann and Meyer, '90), and acetylcholinesterase histochemistry was used to characterize these patterns. A survey of pretectal variation in teleosts reveals that, although there may be more than three patterns of pretectal organization (Northcutt and Wullimann, '88; A.B. Butler, M.F. Wullimann and R.G. Northcutt, unpublished observations), the pattern observed in Osteoglossum can be regarded as the intermediately complex pattern previously described (Wullimann and Meyer, '90). The distribution of the three patterns of pretectal organization indicates that the intermediately complex one is evolutionarily primitive, and the other two are derived (Wullimann and Meyer, '90).

In percomorphs, the parvicellular SPn is a large, pleated nucleus of distinct cytoarchitecture, and it forms the first relay center in a morphologically elaborate array of nuclei and fiber tracts that form a visual pathway from the retina to the hypothalamus via the pretectum (Figs. 10B, 11B). Specifically, the ganglion cells of the contralateral retina project to the parvicellular SPn (Butler and Northcutt, ' 81 ; Ito et al., '84; for more references see Northcutt and Wullimann, '88), whose major efferent target is the intermediate SPn bilaterally (Murakami et al., ' 86 ; Striedter and Northcutt, '86, '89). The intermediate SPn and nucleus corticalis project to the ipsilateral (nucleus corticalis also to the contralateral) nucleus glomerulosus (Sakamoto and Ito, '82; Wullimann and Northcutt, '86). Whether or not the somata of nucleus corticalis neurons receive primary visual input is still in dispute (see Northcutt and Wullimann, '88). Dendrites of nucleus corticalis neurons extend halfway into the optic tectum (Sakamoto and Ito, '82), however, and it is therefore reasonable to assume that these dendrites receive primary (and/or possibly higher order) visual input. Furthermore, electrophysiological data also suggest a visual function of nucleus corticalis (Rowe and Beauchamp, '82).

Nucleus glomerulosus is bilobed, comprising a ventrocaudal main portion (pars posterior) and a smaller portion (pars anterior), which extends dorsorostrally toward the superficial pretectal area (Wullimann, '85; Northcutt and Wullimann, '88). Nucleus glomerulosus, in turn, projects to the ipsilateral inferior lobe of the hypothalamus (Sakamoto and Ito, ' 82 ).

Although Osteoglossum shows the intermediately complex pattern of pretectal organization, its circuitry is similar to that in percomorphs. Retinal ganglion cells project heavily to the contralateral parvicellular SPn (M.F. Wullimann and D.L. Meyer, unpublished observations on horseradish peroxidase material), whose major efferent target is the rostrolateral portion of the posterior pretectal nucleus bilaterally. Another pretectal nucleus, nucleus corticalis, projects bilaterally to the main caudomedial portion of the posterior pretectal nucleus, whose only known efferent target is the ipsilateral inferior lobe of the hypothalamus. In order to exclude the possibility that our nucleus corticalis represents part of the mesencephalic trigeminal nucleus, whose fibers might have been labeled en passage by our DiI applications into the posterior pretectal nucleus, we applied DiI to both trigeminal nerves in one specimen of Osteoglossum. Although these applications labeled no cells in nucleus corticalis, they did label some cells of the mesencephalic trigeminal nucleus.

The hodological similarities of the intermediately complex and elaborate patterns of pretectal organization are striking. In Osteoglossum, although there is no discrete intermediate SPn separate from the posterior pretectal nucleus, the rostrolateral portion of the posterior pretectal nucleus, in contrast to the main caudomedial portion, receives bilateral input from the parvicellular SPn and, in this regard, is similar to the intermediate SPn of percomorphs. Unlike the intermediate SPn, however, the rostrolateral portion of the posterior pretectal nucleus, as well as the caudomedial portion, projects to the inferior lobe. This suggests that the differentation of an intermediate SPn as an additional relay center in the percomorph pattern has evolved as a functional modification in the processing of visual information.

This hodological information strongly supports the hypothesis that the same-named nuclei in the intermediately complex pattern and the elaborate pattern of pretectal organization are homologous. As the presence of a posterior pretectal nucleus is the ancestral condition for teleosts (Wullimann and Meyer, '90) and as this nucleus is similar in its connections to both the intermediate SPn and nucleus glomerulosus, the data also indicate that the posterior pretectal nucleus has developed into the intermediate SPn and nucleus glomerulosus in percomorphs.

The simple pattern of pretectal organization seen in cyprinids is somewhat more difficult to interpret. There is morphological and histochemical evidence that this pattern also comprises three pretectal nuclei--the parvicellular SPn, the magnocellular SPn, and the posterior pretectal nucleus (Wullimann and Meyer, '90) - that are likely homologous to nuclei in the other two patterns. It was recently emphasized, however, that there are non-overlapping, higher order connections of the superficial pretectal nuclei in 


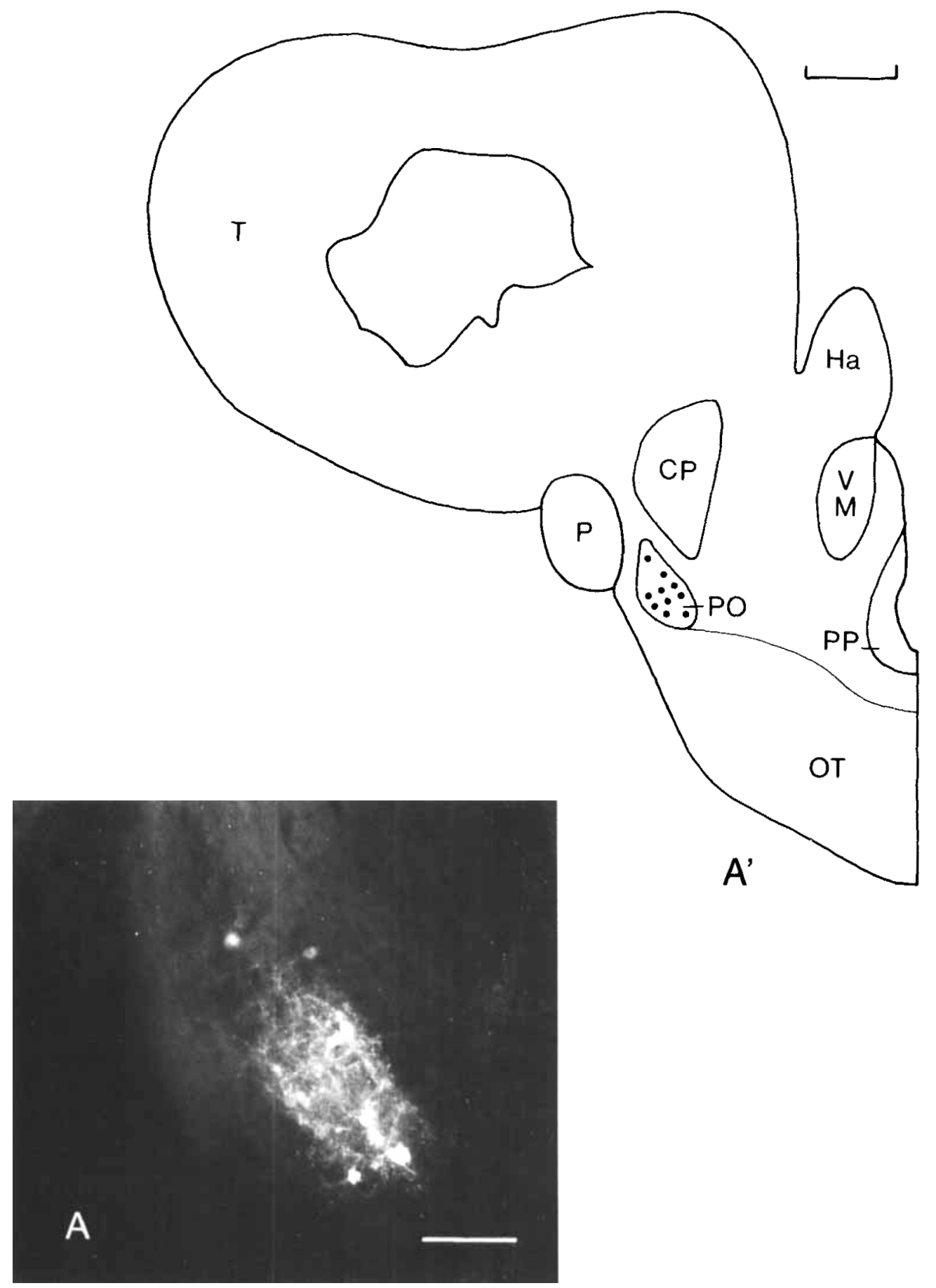

Fig. 9. Photomicrographs (A,B,C,D,E) and corresponding drawings $\left(A^{\prime}, D^{\prime}\right)$ of cross sections showing anterograde and retrograde transport at different levels from rostral (A) to caudal (D) within the posterior pretectal nucleus after application of DiI to the inferior lobe. $\mathbf{E}$ shows a single labeled cell after DiI application to a more ventral area of the inferior lobe. Dendritic morphology of the labeled neuron is visible. See abbreviations list. Bar in $\mathrm{A}^{\prime}$ and $\mathrm{D}^{\prime}=0.25 \mathrm{~mm}$. Bar in $\mathrm{A}=0.1 \mathrm{~mm}$ and applies to $\mathrm{A}-\mathrm{D}$; bar in $\mathrm{E}=0.05 \mathrm{~mm}$. Lateral is to the left.

Fig. 9 continues on pages $428-429$. 


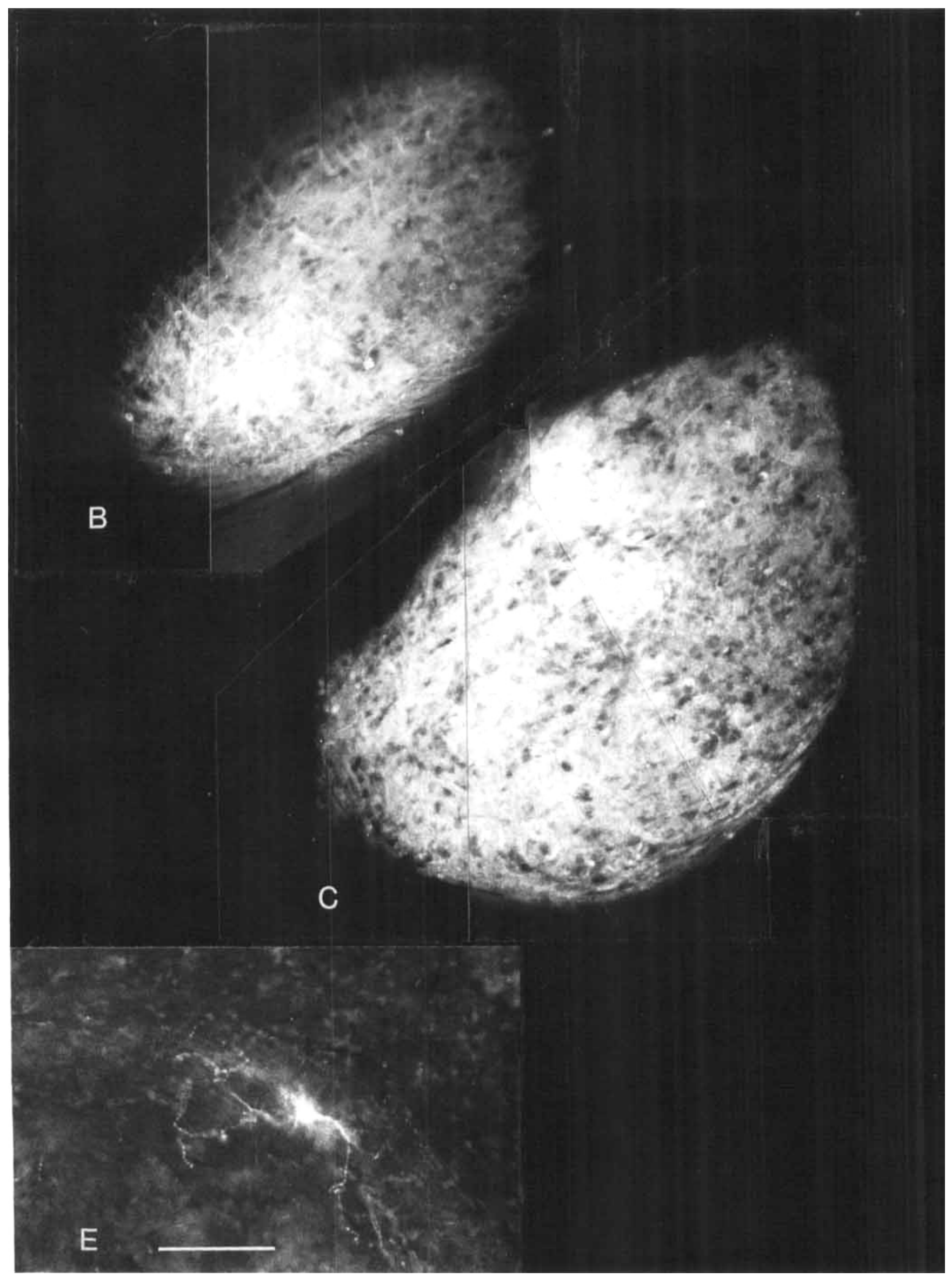




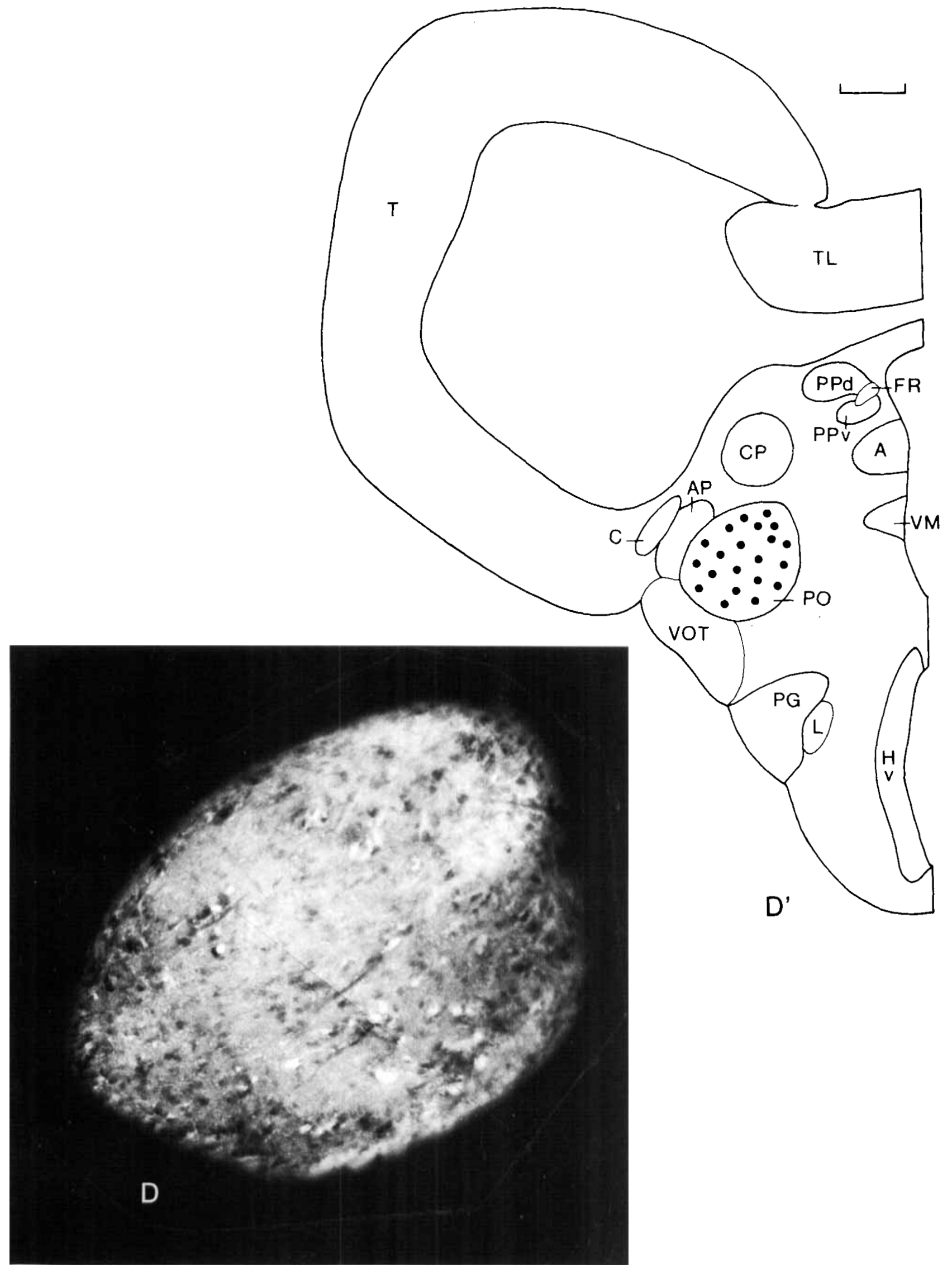

Figure 9D-D' 


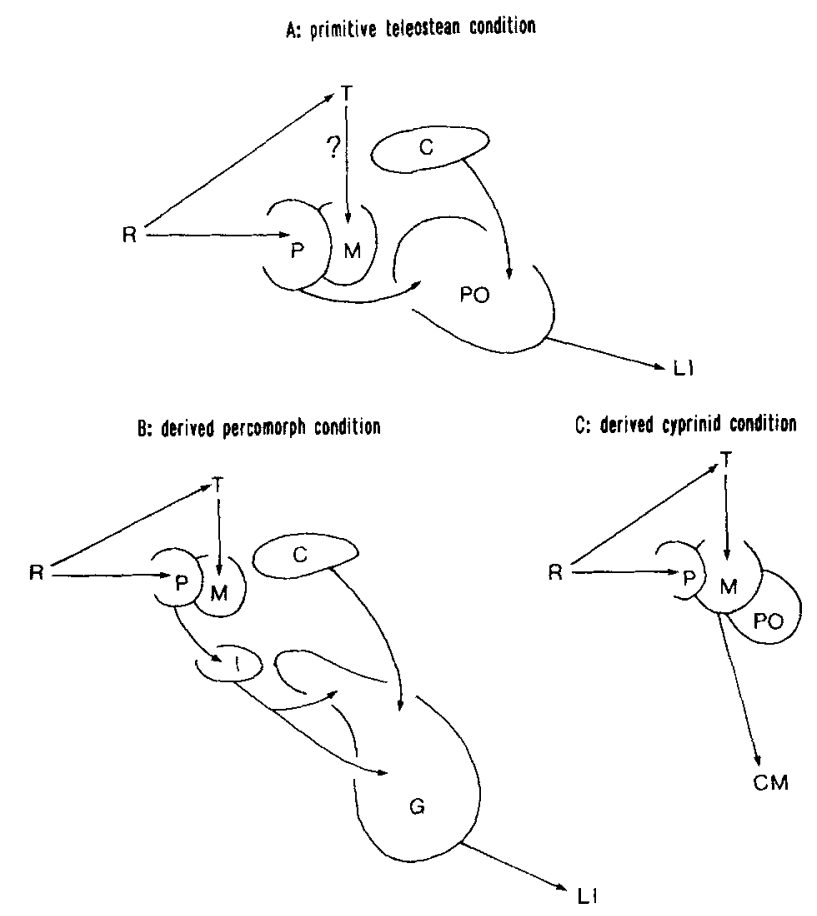

Fig. 10. Diagram showing three patterns of pretectal organization in teleosts and their known visual circuitry to the hypothalamus. The phylogeny of these pretectal patterns is also indicated (after Wullimann and Meyer, '89, '90). A. The ancestral teleostean pattern is intermediate in complexity; circuitry as demonstrated in the present study. B. The derived percomorph pattern is the most complex of the three; for references to circuitry, see Figure 11 and text. Hodological similarities between pretectal patterns A and B support a hypothesis of homology between same-named nuclei. $C$. The derived cyprinid pattern is the least complex of the three; circuitry after Northcutt and Braford ('84). The nuclei and tracts forming visual pathways to the hypothalamus in the ancestral teleostean pattern and the derived percomorph pattern are lost or reduced. However, note a different, non-homologous visual pathway to the hypothalamus. Except for the retinofugal projections originating in the contralateral eye, all other projections are meant to be ipsilateral. See abbreviations list.

percomorphs and cyprinids (Striedter and Northcutt, '89). Indeed, those data on two distinct visual pathways through the superficial pretectum in the percomorph Lepomis differ totally from those on visual pathways in Carassius (Northcutt and Braford, '84), although Striedter and Northcutt ('89) also described a connection from the parvicellular SPn to the inferior raphe not previosly reported in Carassius. Since this connection also exists in other teleosts investigated, Striedter and Northcutt ('89) concluded that Carassius has retained this one visual pathway through the parvicellular SPn but has lost others, such as the connection with the posterior pretectal nucleus observed in the present study. This interpretation is supported by our findings on the connections of the parvicellular SPn in Osteoglossum, where three connections of this nucleus are the same as in Lepomis (efferents to the rostrolateral part of the posterior pretectal nucleus and afferents from nucleus isthmi and the optic tectum; compare A and B in Fig. 11). Two additional tracts in Osteoglossum can be followed toward the other two efferent targets (inferior raphe, trochlear motor nucleus) of the parvicellular SPn in Lepomis (Striedter and Northcutt, ' 89 ). This indicates that the connections of the parvicellular SPn observed in Lepomis are plesiomorphic (evolutionarily primitive) for teleosts, as these connections are also found in an outgroup of percomorphs and cyprinids.

In summary, the data on Lepomis, Osteoglossum, and Carassius indicate that homologous visual pathways to the hypothalamus found in the intermediately complex and elaborate pretectal patterns are absent in the simple pretectal pattern observed in Carassius. There is, however, a non-homologous visual pathway to the hypothalamus in Carassius (Fig. 10C), leading through the magnocellular SPn.

It is well established that the magnocellular SPn in Carassius receives tectal input (see Northcutt and Wullimann, '88). Northcutt and Braford ('84) have found that this nucleus projects to the so-called mammillary body and the nucleus lateralis valvulae. As these connections obviously do not overlap with those of the magnocellular SPn in percomorphs, Striedter and Northcutt ('89) hypothesized that the nucleus is not homologous in cyprinids and other teleosts. In cyprinids (and in most other teleosts), however, its position is medial to the parvicellular SPn; it receives a tectal input (Grover and Sharma, '79; Luiten, '81), and it has strong acetylcholinesterase activity (Ekström, '87; Wullimann and Meyer, '89, '90). These facts support the alternative hypothesis, that the magnocellular SPn in cyprinids and other teleosts is homologous, and that the nucleus has changed its cytoarchitecture and efferent connections during the evolution of cypriniform teleosts. However, before one can distinguish between these two hypotheses, additional hodological and histochemical studies on the magnocellular SPn need to be conducted (1) in percomorphs, (2) in cypriniforms and other ostariophysines, and (3) in the outgroups of these two major teleost groups.

\section{Comparison between teleosts and other vertebrates}

Homologous nuclei and fiber tracts forming visual pathways to the hypothalamus, as just described in teleosts, have not been indicated in other vertebrates, either by connectivity or by acetylcholinesterase histochemistry. Thus, as noted above, we interpret these pathways in teleosts as a derived feature.

A totally different system of visual pathways to the hypothalamus, however, does exist in all vertebrates examined, and it is particularly well understood in several species of mammals, such as rats, hamsters, mongolian gerbils, and cats. The circuitry has been described as follows: ganglion cells of the eye project bilaterally to the suprachiasmatic nucleus (Hendrickson et al., '72; Moore and Lenn, '72). This nucleus also receives bilateral second-order visual input from a portion (the intergeniculate leaflet) of the (retinorecipient) lateral geniculate nucleus (Swanson et al., '74; Pickard, '82; Card and Moore, '89; Mikkelsen, '90). The suprachiasmatic nucleus, in turn, projects to other hypothalamic regions, and the projection is particularly strong to the anterior hypothalamus (Watts et al., '87).

Functionally, this system is related to phenomena of circadian rhythms (Moore, '82). The light/dark cycle of the environment is the signal that entrains the endogenous biological clock (pacemaker) located in the neurons of the suprachiasmatic nucleus to the external 24-hour periodicity (Moore, '82). This signal is primarily transmitted to the suprachiasmatic nucleus by way of direct retinal input. Additional visual input from the intergeniculate leaflet has been suggested to play "a role as a second order fine tuner 


\section{A: OSTEOGLOSSUM}

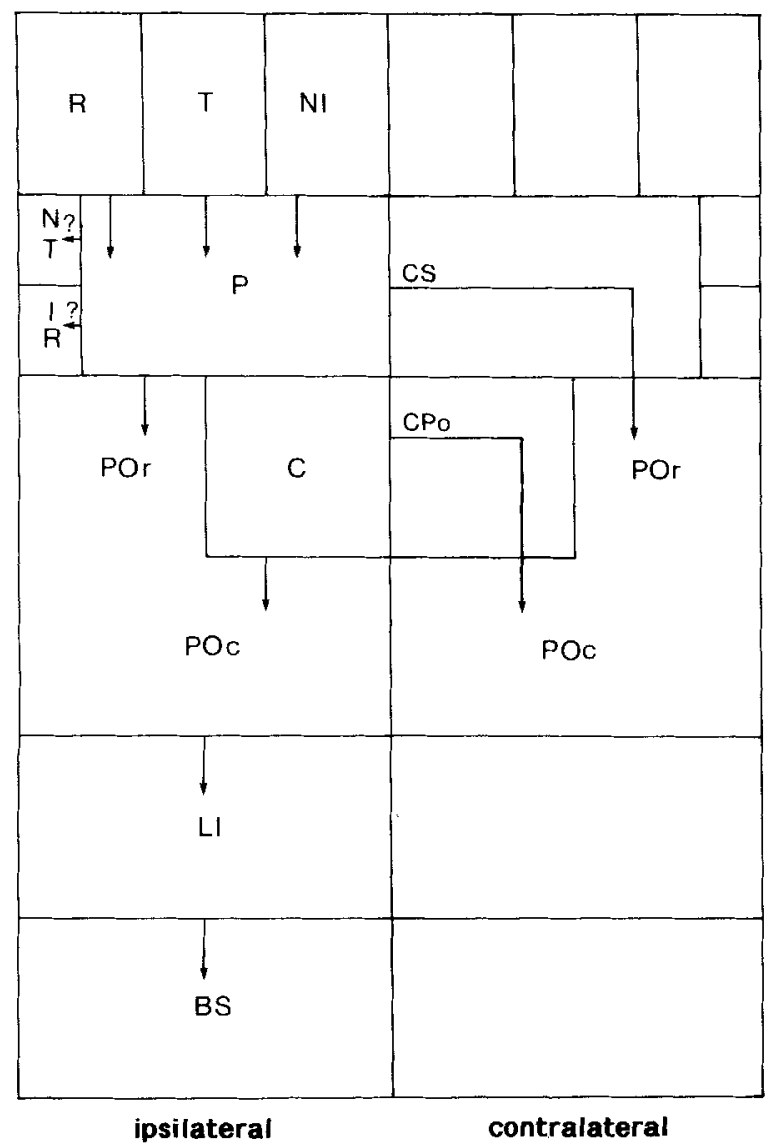

Fig. 11. Schematic diagram shows the known circuitry of the visual pathways to the hypothalamus in Osteoglossum, which displays the intermediately complex pretectal pattern (A), and in percomorph teleosts, which have the elaborate pretectal pattern (B). Left and right part of (A) and (B) represent ispilateral and contralateral brain sides, respectively. Spatial organization of compartments reflects our interpretation of homologies between nuclei in pretectal patterns A and B. Note that the rostrolateral portion of the posterior pretectal nucleus in

of the suprachiasmatic nucleus oscillator to changing ambient light conditions"' (Pickard, '82:81).

This central nervous circadian system is best understood in mammals. Its presence, however, can be assumed in teleosts as well, since a direct visual projection to a suprachiasmatic nucleus has been observed in all species examined (see Northcutt and Wullimann, '88). In contrast to the suprachiasmatic nucleus, the visual pathways to the hypothalamus that we describe and discuss in the present work are not likely to be primarily involved in circadian rhythmicity. What little electrophysiological evidence is available points in a quite different direction. Intracellular recordings from nucleus corticalis neurons, which form the major input to the posterior pretectal nucleus (or, depending on the species, to the nucleus glomerulosus), show that these neurons are responsive to small moving spots on a contrasting background (Rowe and Beauchamp, '82). This suggests that the visual pathways to the hypothalamus that we are concerned with here deal with spatial information of the visual world rather than with the light/dark cycle of environmental light. It has been suggested that this spatial information is used in predation by highly visual teleosts (Rowe and Beauchamp, '82). The new connectional data
B: LEPOMIS, NAVODON

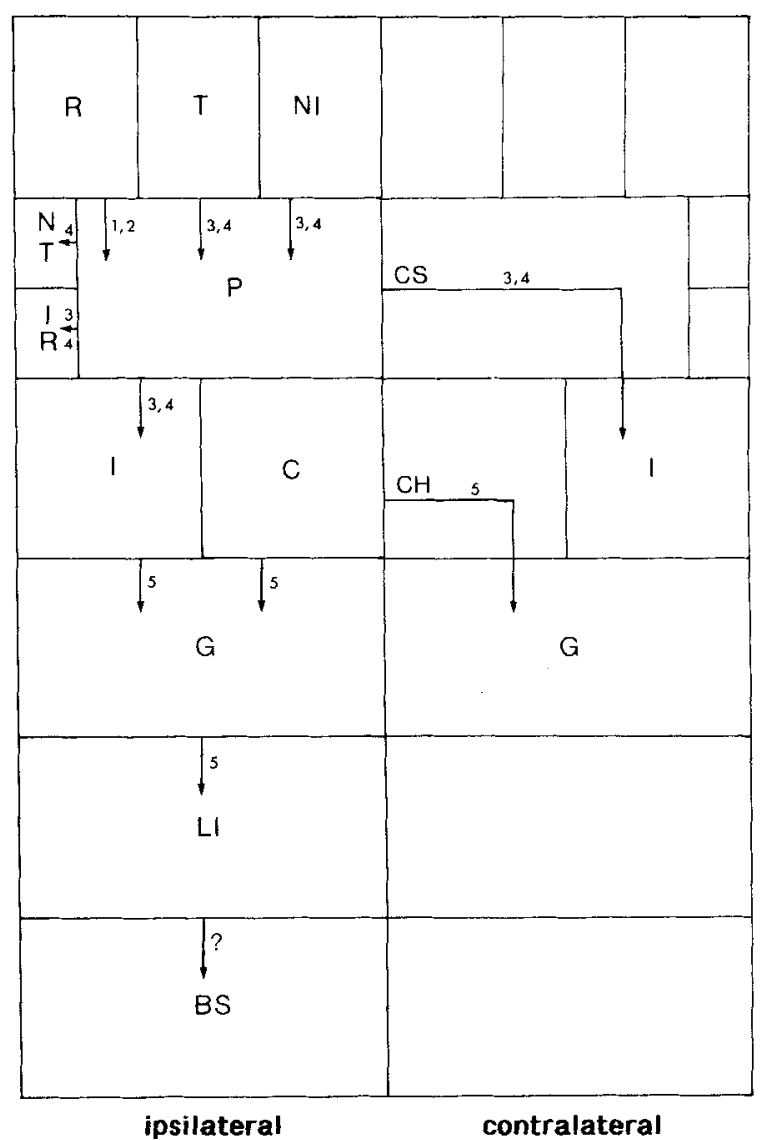

pattern $A$ is homologous to the intermediate superficial pretectal nucleus in pattern B. Furthermore, it is important to note that the caudomedial portion of the posterior pretectal nucleus in pattern $\mathrm{A}$ is homologous to nucleus glomerulosus in pattern B. Numbers refer to connections established by 1:Ito et al. ('84) 2:Butler and Northcutt ('81) 3:Murakami et al. ('86) 4:Striedter and Northcutt ('86;'89) 5:Sakamoto and Ito ('82). See abbreviations list.

(present study; Striedter and Northcutt, '89) and histochemical information (Wullimann and Meyer, '90) discussed earlier offer new possibilities for a functional investigation of these massive visual pathways to the hypothalamus in teleosts.

\section{History of pretectal nomenclature}

The major advances in understanding nuclei and fiber tracts that form visual pathways to the hypothalamus are discussed. To minimize confusion, we have adopted a consistent procedure: in general, we use Braford and Northcutt's ('83) terminology to designate neural structures; where designations of earlier authors differ from ours, their terms are given in parantheses. The use of pretectal nomenclature is summarized in Tables 1-3.

Although Baudelot (1869) mentioned (but did not illustrate) a nucleus that likely represents nucleus glomerulosus in Gasterosteus (his nodule commissural), Fritsch's seminal paper "Untersuchungen über den feineren Bau des Fischgehirns" (1878) first describes and illustrates an unambiguous nucleus glomerulosus (his nucleus rotun$d u s)$. Fritsch (1878) also discussed additional structures of 
TABLE 1. Terminology for Certain Diencephalic and Pretectal Nuclei in Teleosts: Superficial Pretectum

\begin{tabular}{|c|c|c|c|}
\hline $\begin{array}{l}\text { present study; Wullimann and Meyer, '90; } \\
\text { Northcutt and Wullimann, ' } 88 \text {; Braford } \\
\text { and Northcutt, ' } 83\end{array}$ & $\begin{array}{l}\text { nucleus pretectalis superficialis pars } \\
\text { parvoceliularis (P) }\end{array}$ & $\begin{array}{l}\text { nucleus pretectalis superficialis pars } \\
\text { magnocellularis }(M)\end{array}$ & $\begin{array}{l}\text { nucleus pretectalis superficialis pars } \\
\text { intermedius (I) }\end{array}$ \\
\hline Baudelot, 1869 & - & - & - \\
\hline Fritsch, 1878 & corpus geniculatum externum & - & - \\
\hline Haller, 1898 & nucleus lateralis opticus (in part) & nucleus lateralis opticus (in part) & -- \\
\hline Goldstein, '05 & corpus geniculatum & nucleus praetectalis (in Salma) & - \\
\hline Ariëns Kappers, '06 & corpus geniculatum laterale (in part) & corpus geniculatum laterale (in part) & - \\
\hline Franz, '12 & corpus geniculatum & nucleus anterior thalami ${ }^{1}$ (in part) & - \\
\hline Sheldon, '12 & corpus geniculatum laterale & nucleus anterior thalami (in part) & -- \\
\hline Holmgren, '20 & nucleus geniculatus & nucleus pretectalis & $\ldots$ \\
\hline Burr, '28 & lateral geniculate body (in part) & lateral geniculate body (in part) & lateral geniculate body (in part) \\
\hline Brickner, '29 & corpus geniculatum (in part) & corpus geniculatum (in part) & nucleus intermedius \\
\hline Bergquist, '32 & corpus geniculatum laterale mesencephali & nucleus praetectalis & - \\
\hline Meader, '34 & corpus geniculatum laterale ipsum & $\begin{array}{l}\text { corpus genieulatum posterius pars } \\
\text { ventralis }\end{array}$ & corpus geniculatum posterius pars dorsalis \\
\hline Schnitzlein, '62 & nucleus geniculatus lateralis & $\begin{array}{l}\text { nucleus rotundus }{ }^{1} \text { (in part) } \\
\text { nucleus pretectalis }{ }^{2}\end{array}$ & nucleus rotundus ${ }^{3}$ \\
\hline Peter and Gill, '75 & nucleus lateral geniculatus & nucleus rotundus & - \\
\hline
\end{tabular}

${ }^{1}$ In cyprinids.

${ }^{2}$ In non-cyprinids

${ }^{3}$ In perciforms.

TABLE 2. Terminology for Certain Diencephalic and Pretectal Nuclei in Teleosts: Nucleus Glomerulosus and Posterior Pretectal Nucleus

\begin{tabular}{|c|c|c|c|}
\hline & Paracantho- + acanthopterygians & Other teleosts (except cyprinids) & Cyprinids \\
\hline $\begin{array}{l}\text { present study; Wullimann and Meyer, '90; } \\
\text { Northeutt and Wullimann, ' } 88 \text {; Braford } \\
\text { and Northcutt, ' } 83\end{array}$ & nucleus glomerulosus (G) & posterior pretectal nucleus ( $\mathrm{PO}$ ) & posterior pretectal nucleus $(\mathrm{PO})$ \\
\hline Baudelot, 1869 & nodule commissural & - & - \\
\hline Fritsch, 1878 & nucleus rotundus & - & - \\
\hline Haller, 1898 & - & nucleus lateralis opticus (in part) & - \\
\hline Goldstein, '05 & - & nucleus anterior thalami & - \\
\hline Arjëns Kappers, '06 & nucleus rotundus & - & - \\
\hline Franz, '12 & corpus glomerosum & nucleus anterior thalami & nucleus anterior thalami (in part) \\
\hline $\begin{array}{l}\text { Sheldon, '12 } \\
\text { Holmgren, '20 }\end{array}$ & $\begin{array}{l}\text { nucleus rotundus }+ \text { nucleus anterior } \\
\text { thalami }\end{array}$ & $\begin{array}{l}\text { nucleus rotundus + nucleus anterior } \\
\text { thalami }\end{array}$ & \\
\hline Burr, '28 & nucleus rotundus & - & - \\
\hline Brickner, '29 & $\begin{array}{l}\text { corpus glomerulosum (pars rotunda }+ \\
\text { pars anterior) }\end{array}$ & $\begin{array}{l}\text { corpus glomerulosum (pars rotunda }+ \\
\text { pars anterior) }\end{array}$ & - \\
\hline Bergquist, ' 32 & - & $\begin{array}{l}\text { nucleus rotundus + nucleus anterior } \\
\text { thalami }\end{array}$ & - \\
\hline Meader, ' 34 & $\begin{array}{l}\text { corpus glomerosum pars rotundus + pars } \\
\text { anterior }\end{array}$ & - & - \\
\hline Schnitzlein, '62 & nucleus glomerulosus & nucleus rotundus & nucleus rotundus (in part) \\
\hline Peter and Gill, '75 & - & - & nucleus rotundus \\
\hline
\end{tabular}

TABLE 3. Terminology for Certain Diencephalic and Pretectal Nuclei in Teleosts: Additional Nuclei

\begin{tabular}{|c|c|c|c|}
\hline $\begin{array}{l}\text { present study; Wullimann and Meyer, '90; } \\
\text { Northcutt and Wullimann, ' } 88 \text {; Braford and } \\
\text { Northcutt, ' } 83\end{array}$ & preglomerular nuclei $(\mathrm{PG})$ & nucleus anterior thalami (A) & nucleus corticalis (C) \\
\hline Baudelot $_{7} 1869$ & - & - & - \\
\hline Fritsch, 1878 & - & - & nucleus corticalis \\
\hline Haller, 1898 & nucleus rotundus & nucleus anterior thalami & nucleus corticalis \\
\hline Goldstein, '05 & nucleus ventralis thalami & - & nucleus corticalis (in Salmo) \\
\hline Arjëns Kappers, '06 & nucleus praerotundus & nucleus anterior thalami & nucleus corticalis \\
\hline Franz, '12 & nucleus ventralis thalami & - & - \\
\hline Sheldon, '12 & nucleus prerotundus + nucleus rotundus & nucleus post-habenularis & - \\
\hline Holmgren, "20 & nucleus prerotundus & eminentia thalami & nucleus corticalis \\
\hline Burr, '28 & nucleus prerotundus & eminentia medialis & nucleus pretectalis \\
\hline Brickner, '29 & - & nucleus tegmenti motorius ventralis & nucleus corticalis \\
\hline Bergquist, 32 & nucleus praerotundus & nucleus dorsalis thalami & - \\
\hline Meader, ' 34 & nucleus prethalamicus (in part) & - & nucleus corticalis \\
\hline Schnitzlein, ' 62 & nucleus preglomerulosus & $\begin{array}{l}\text { nucleus dorsomedialis + dorsolateralis } \\
\text { thalami (in part) }\end{array}$ & nueleus corticalis \\
\hline Peter and Gill, '75 & $\begin{array}{l}\text { nucleus preglomerulosus + nucleus } \\
\text { giomerulosus }\end{array}$ & $\begin{array}{l}\text { nucleus dorsomedialis + dorsolateralis } \\
\text { thalami (in part) }\end{array}$ & - \\
\hline
\end{tabular}

relevance here: nucleus corticalis, commissura horizontalis, and parvicellular SPn (Fritsch's corpus geniculatum externum). Although he reported on a variety of teleost species, his plates document that nucleus glomerulosus (Fritsch's nucleus rotundus) was identified only in derived teleosts (paracanthopterygians-Lophius piscatorius; acanthopterygians-Scorpaena porcus, Serranus scriba, Labrus mixtus, Scophthalmus (=Rhombus) maximus). Fritsch suggested that the inferior lobe in teleosts may represent the corpus mammillare (his corpus candicans). Thus his designation of "rotundus" for nucleus glomerulosus was solely intended to describe the form of a nucleus, which was considered to be part of the hypothalamus due to its close topological relationship with the "corpus mammillare." However, Fritsch was explicitly cautious in homologizing this nucleus in fishes and humans.

Later, C.L. Herrick (1892a,b) offered an alternative view: the inferior lobe in teleosts represents the substantia nigra 
rather than a homologue to the corpus mammillare in humans. Thus he interpreted the nucleus glomerulosus (nucleus rotundus of Fritsch) "unhesitatingly ... as the nidulus ruber" (Herrick, 1892a:60). Today, both hypotheses remain vivid testimony of the late nineteenth-century's Zeitgeist and the tendency toward anthropocentric interpretations, even in vertebrates as remote from humans as teleosts.

Fritsch (1878) also provided an accurate morphological description of the nucleus corticalis in teleosts. The term, still used today (Table 3), relates to the close topological relationship of the nucleus to the "Rindenschichten" (cortical layers). In Fritsch's terminology, the Rindenschichten include all tectal layers except the periventricular gray-andwhite zones and the stratum marginale and stratum opticum.

Fritsch described the pretectal and diencephalic morphology in derived teleosts. Subsequent researchers, describing more ancestral teleosts with different pretectal neuroanatomy, misidentified nucleus glomerulosus (nucleus rotundus of Fritsch) in two ways.

In derived teleosts, nucleus glomerulosus (nucleus rotundus of Fritsch) extends far enough ventral to be partly surrounded by the preglomerular cell masses (see Fig. 1B). In teleosts without a nucleus glomerulosus, the preglomerular complex or parts of it were subsequently misinterpreted as nucleus glomerulosus (nucleus rotundus of Fritsch), e.g., by Haller (1898) in Salmo. Consequently, Haller (1898) had to use a different term for the large pretectal nucleus, located dorsal to the preglomerular cell masses, the nucleus that we believe is homologous to nucleus glomerulosus. He designated it nucleus opticus lateralis (in Salmo). At the same time, Haller introduced the term nucleus anterior thalami for a nucleus in the medial dorsal thalamus of teleosts (see Fig. 1); this term is still used today (Table 3).

Similarly, Goldstein ('05) also did not find the typically shaped nucleus rotundus of Fritsch embedded within the preglomerular cell aggregates in cyprinids and salmonids. Unlike Haller, however, he named the preglomerular complex nucleus ventralis thalami, as it did not appear round, and explicitly stated that the name replaced nucleus rotundus of Fritsch. Furthermore, Goldstein ('05) termed the magnocellular SPn in cyprinids and the posterior pretectal nucleus in salmonids nucleus anterior thalami, thus ignoring the different usage of this term by Haller (1898) and Catois ('02).

In addition to the misinterpretation of the preglomerular cell masses as nucleus glomerulosus (nucleus rotundus of Fritsch), a second misidentification occurred in cyprinids. The posterior pretectal nucleus in these fishes is very small and located immediately adjacent, caudally, to the large magnocellular SPn (Wullimann and Meyer, '90). The two were often treated as a single nucleus and jointly named nucleus rotundus of Fritsch (e.g., in Barbus-Mayser, 1882).

Viktor Franz ('12) achieved the next qualitative step. Like many of his colleagues, Franz looked at a variety of teleost species. He, however, did not attempt to describe a model of THE fish brain. Rather, he recognized different patterns of pretectal organization in different teleost groups. Franz stated unambiguously that, depending on the species, there is either a nucleus glomerulosus (his corpus glomerosum, which he described in paracanthopterygians and acanthopterygians) or a posterior pretectal nucleus (his nucleus anterior thalami, which he described in Clupea and
Salmo). Although the two nuclei clearly differ in histology and position within the diencephalon, Franz suggested that they may be homologous. This hypothesis is supported by the present hodological study. Despite the clarity of Franz's statements, many subsequent authors described his $n u$ cleus anterior thalami as a rostral extension of nucleus glomerulosus (nucleus rotundus of Fritsch), thereby implying that the two nuclei are present in all species (Holmgren, '20; Brickner, '29; Bergquist, '32).

We agree with Franz regarding the morphology and interpretation of two different neuroanatomical patterns and his major message: nucleus glomerulosus (seen in paracanthopterygians and acanthopterygians) is homologous to nucleus anterior thalami of Goldstein (seen in other teleosts). Nevertheless, we do not use the term nucleus anterior thalami for the posterior pretectal nucleus, because a different nucleus, located more medial within the dorsal thalamus, has previously been so designated (Haller, 1898; Catois, '02; Ariëns Kappers, '06; see Fig. 1 and Table 3). Priority and comparative morphological and hodological considerations favor our retaining nucleus anterior thalami to designate this medially located nucleus (Braford and Northcutt, '83).

In cyprinids the posterior pretectal nucleus is small and located directly caudal to the magnocellular SPn. Franz ('12), therefore, did not recognize the two as separate nuclei in Carassius and named this nuclear aggregate nucleus anterior thalami. He correctly described, however, that a tractus thalamo-mammillaris emerges from his nucleus anterior thalami in Carassius. As discussed earlier, this connection originates in the magnocellular SPn and has subsequently been confirmed with modern tracer techniques (Northcutt and Braford, '84). Franz further described a large tract leading from the posterior pretectal nucleus (his anterior thalamic nucleus) of Salmo and Clupea or from nucleus glomerulosus (his corpus glomerosum) in various paracanthopterygians and acanthopterygians to the hypothalamus. He interpreted this connection as the homologue of the tractus thalamo-mammillaris he described in the goldfish. As noted, a more detailed cytoarchitectonic and hodological analysis of the pretectum in teleosts demonstrates that these two pathways to the hypothalamus are not homologous.

Mazzi's ('53) extensive study of nucleus glomerulosus (his corpo glomerulare) in 79 teleost species supports Franz's concept of the existence of at least two different neuroanatomical patterns. Mazzi concluded that only derived teleosts (neoteleosts in the taxonomy of Lauder and Liem, '83) possess a rotundal (our posterior) part of nucleus glomerulosus and that more ancestral teleosts have a more rostrodorsally located anterior nucleus. Depending on the species, this nucleus corresponds to our intermediate $\mathrm{SPn}$ or posterior pretectal nucleus.

The history of the nomenclature regarding the superficial pretectum is somewhat less confusing. Whereas most researchers have recognized at least the parvicellular SPn (lateral geniculate nucleus of most studies, see Table 1), fewer of them described an additional magnocellular SPn (nucleus pretectalis of most authors, see Table 1). Burr ('28) recognized a tripartition of the superficial pretectum (his lateral geniculate body), and Brickner ('29) designated a third-the intermediate-nucleus in the superficial pretectum of percomorphs (his nucleus intermedius).

Much of the confusion in terminology arose from the misidentifications of various nuclei already designated by previous authors. Schnitzlein ('62), however, created an 
additional source of confusion. He designated a lateral geniculate nucleus and a nucleus rotundus in Carassius in order to imply homology with the same-named dorsal thalamic nuclei in tetrapods. Thus only by chance was his nucleus rotundus in Carassius synonymous with that of older authors, who intended to homologize the magnocellular SPn with the hypothalamic nucleus rotundus of Fritsch. Peter and Gill's ('75) often used atlas of the brain of Carassius perpetuates much of Schnitzlein's terminology.

In an attempt to eliminate some of the confusion in nomenclature, Braford and Northcutt ('83) interpreted the diencephalic and mesencephalic morphology in teleosts in a comparative context. New hodological information necessitated new terminology for a few nuclei. These authors considered the retinofugal lateral geniculate nucleus and the tectofugal nucleus rotundus of Schnitzlein ('62) to be the parvicellular SPn and magnocellular SPn, respectively. There are two convincing arguments for this interpretation: (1) the absence of telencephalic projections from Schnitzlein's lateral geniculate nucleus and nucleus rotundus, and (2) the existence of such projections from nuclei of the dorsal thalamus in some teleosts (see also Northcutt and Wullimann, '88). Consequently, the nucleus intermedius of Brickner ('29) was later interpreted as a third part-pars intermedius-of the superficial pretectum (Northcutt and Wullimann, '88). Since Braford and Northcutt ('83) dealt with a cyprinid species, they did not explicitly recognize a homologue of nucleus glomerulosus as seen in percomorph teleosts (nucleus rotundus of Fritsch). However, a small pretectal nucleus, recognized by these authors in Carassius, corresponds to the posterior pretectal nucleus of Wullimann and Meyer ('90). Braford and Northcutt ('83) did not name it nucleus anterior thalami of Franz ('12), because a more medially located dorsal thalamic nucleus with the same name existed in the literature (see above). On the basis of acetylcholinesterase histochemistry, Wullimann and Meyer ('90) later suggested that the small posterior pretectal nucleus in Carassius is homologous to the large nucleus seen in many non-neoteleost species, such as Osteoglossum. They termed it posterior pretectal nucleus (nucleus anterior thalami of Franz). Based on connectivity, the present work argues that it is homologous to the intermediate SPn and nucleus glomerulosus of percomorphs. As is true of the dorsal pallium of reptiles and the wulst of birds, the organization of the posterior pretectal nucleus in ancestral teleosts and that of the intermediate SPn plus nucleus glomerulosus in derived teleosts is sufficiently different to justify the use of different terms for homologous brain areas.

\section{Conclusions}

Several conclusions can be drawn from the present study. 1. The rostrolateral and the caudomedial parts of the posterior pretectal nucleus in Osteoglossum are homologous to the intermediate SPn and nucleus glomerulosus, respectively, in percomorphs. This may be true for all teleosts possessing a posterior pretectal nucleus. 2 . In combination with data on the phylogenetic distribution of pretectal nuclei in teleosts (Northcutt and Wullimann, '88; Wullimann and Meyer, ' 90 ) the circuitry of the posterior pretectal nucleus described here in Osteoglossum supports the hypothesis that a relatively undifferentiated posterior pretectal nucleus is the plesiomorphic condition for teleosts. A more differentiated nucleus glomerulosus and a separate intermediate SPn thus represent an apomorphic (derived) condition in some teleosts. Furthermore, the circuitry in Osteoglossum supports the hypothesis that the intermediately complex pattern of pretectal organization and its circuitry is plesiomorphic, whereas the elaborate and the simple pretectal patterns and their circuitry are both apomorphic. 3. Nucleus glomerulosus is a pretectal rather than a preglomerular (thalamic) division, which has been displaced in ontogeny and phylogeny and, as a result, is located within the boundaries of preglomerular cell masses.

\section{ACKNOWLEDGMENTS}

Thanks are due to Georg F. Striedter for introducing one of the authors (M.F.W.) to the wizardry of the DiI technique and for many lively discussions in La Jolla to Dr. Ann B. Butler for commenting on the manuscript, and to Kristina Wullimann for developing a specific protocol for embedding and cutting small brains on the vibratome. We also thank Rod Dungan and Sieglinde Rülke for making the photographic reproductions, and Mary Sue Northcutt for extensive help with the manuscript. This work was supported by the Swiss National Science Foundation and the JanggenPöhn-Stiftung (M.F.W.), the German Science Foundation (D.L.M.), and (United States) NIH grants NS24669 and NS24869 (R.G.N.).

\section{LITERATURE CITED}

Ariëns Kappers, C.U. (1906) The structure of the teleostean and selachian brain. J. Comp. Neurol. 16:1-109.

Baudelot, M. (1869) Observation sur un petit centre nerveux qui se trouve en rapport avec le faisceau posterieur de la commissure de Haller chez l'epinoche. Bull. Soc. Sci. Nat. Strasbourg 3:37-40.

Bergquist, H. (1932) Zur Morphologie des Zwischenhirns bei niederen Wirbeltieren. Acta Zool, 13:57-304.

Braford, M.R. Jr., and R.G. Northcutt (1983) Organization of the diencephalon and pretectum of the ray-finned fishes. In R.E. Davis and R.G. Northcutt (eds): Fish Neurobiology, Vol. 2. Ann Arbor: University of Michigan Press, pp. 117-163.

Brickner, R.M. (1929) A description and interpretation of certain parts of the teleostean midbrain and thalamus. J. Comp. Neurol. 47:225-282.

Burr, H.S. (1928) The central nervous system of Orthagoriscus mola. J. Comp. Neurol. 45:33-128.

Butler, A.B., and R.G. Northcutt (1981) Retinal projections in the green sunfish: A case of homoplasy. Soc. Neurosci. Abstr. 7:84.

Card, J.P., and R.Y. Moore (1989) Organization of lateral geniculatehypothalamic connections in the rat. J. Comp. Neurol. 284:135-147.

Catois, E.H. (1902) Recherches sur l'histologie et l'anatomie microscopique de l'encephale chez les poissons. Bull. Sci. France et Belgique 26:1-166.

Ekström, P. (1987) Distribution of choline acetyltransferase-immunureactive neurons in the brain of a cyprinid teleost (Phoxinus phoxinus L.). J. Comp. Neurol. 256:494-515.

Franz, V. (1912) Beiträge zur Kenntnis des Mittelhirns und Zwischenhirns der Knochenfische. Folia Neuro-Biologica 6:402-441.

Fritsch, G. (1878) Untersuchungen über den feineren Bau des Fischgehirns. Berlin: Verlag der Gutmann'schen Buchhandlung.

Godement, P., J. Vanselow, S. Thanos, and F. Bonhoeffer (1987) A study in developing visual systems with a new method of staining neurones and their processes in fixed tissue. Development 101:697-713.

Goldstein, K. (1905) Untersuchungen über das Vorderhirn und Zwischenhirn einiger Knochenfische (nebst einigen Beiträgen über Mittelhirn und Kleinhirn derselben). Arch. Mikrosk. Anat. 66:135-219.

Grover, B.G., and S.C. Sharma (1979) Tectal projections in the goldfish (Carassius auratus): A degeneration study. J. Comp. Neurol. 184:435454

Haller, B. (1898) Vom Bau des Wirbelthiergehirns. I. Theil. Salmo und Scyllium. Morphol. Jahrbuch 26:345-641.

Hendrickson, A.E., N. Wagoner, and W.M. Cowan (1972) An autoradiographic and electron microscopic study of retino-hypothalamic connections. Z. Zellforsch. 135:1-26. 
Herrick, C.L. (1892a) Contribution to the morphology of the brain of bony fishes. II. Studies on the brain of some American freshwater fishes. C. Histology of the diencephalon and mesencephalon. J. Comp. Neurol $2: 21-72$

Herrick, C.L. (1892b) Additional notes on the teleost brain. Anat. Anz. $7: 422-431$.

Holmgren, N. (1920) Zur Anatomie und Histologie des Vorder-und Zwischenhirns der Knochenfische. Acta Zool. (Stockh.) 1:137-315.

Honig, M.G., and R.I. Hume (1989) Dil and DiO: Versatile fluorescent dyes for neuronal labelling and pathway tracing. TINS 12:333-341

Ito, H., and R. Kishida (1975) Organization of the teleostean nucleus rotundus. J. Morphol. 147:89-107.

Ito, H., H. Vanegas, T. Murakami, and Y. Morita (1984) Diameters and terminal patterns of retinofugal axons in their target areas: An HRP study in two teleosts (Sebastiscus and Navodon). J. Comp. Neurol. 230:179-197.

Lauder, G.V., and K.F. Liem (1983) The evolution and interrelationships of the actinopterygian fishes. Bull. Mus. Comp. Zool. 150:95-197.

Luiten, P.G.M. (1981) Afferent and efferent connections of the optic tectum in the carp (Cyprinus carpio L.). Brain Res. 220:51-65.

Mayser, P. (1882) Vergleichend-anatomische Studien über das Gehirn der Knochenfische mit besonderer Berücksichtigung der Cyprinoiden. Z Wiss. Zool. 36:259-364.

Mazzi, V. (1953) Il corpo glomerulare del talamo degli attinotterigi. Pubbl. Stn. Zool. Napoli 24:373-433.

Meader, R.G. (1934) The optic system of the teleost, Holocentrus. I. The primary optic pathways and the corpus geniculatum complex. J. Comp. Neurol. 60:361-407.

Mikkelsen, J.D. (1990) Projections from the lateral geniculate nucleus to the hypothalamus of the mongolian gerbil (Meriones unguiculatus): An anterograde and retrograde tracing study. J. Comp. Neurol. 299:493508.

Moore, R.Y. (1982) The suprachiasmatic nucleus and the organization of a circadian system. TINS 5:404-407.

Moore, R.Y., and N.J. Lenn (1972) A retinohypothalamic projection in the rat. J. Comp. Neurol. 146:1-14.

Murakami, T., Y. Morita, and H. Ito (1986) Cytoarchitecture and fiber connections of the superficial pretectum in a teleost, Navodon modestus. Brain Res. 373:213-221.

Northcutt, R.G., and M.R. Braford, Jr. (1984) Some efferent connections of the superficial pretectum in the goldfish. Brain Res. 296:181-184

Northcutt, R.G., and M.F. Wullimann (1988) The visual system in teleost fishes: Morphological patterns and trends. In J. Atema, R.R. Fay, A.N. Popper, and W.N. Tavolga (eds): Sensory Biology of Aquatic Animals. New York: Springer, pp. 515-552.

Peter, R.E., and V.E. Gill (1975) A stereotaxic atlas and technique for forebrain nuclei of the goldfish, Carassius auratus. J. Comp. Neurol. 159:69-102
Pickard, G.E. (1982) The afferent connections of the suprachiasmatic nucleus of the golden hamster with emphasis on the retinohypothalamic projection. J. Comp. Neurol. 211:65-83.

Quinn, B., and E. Weber (1988) M-phenylenediamine: A novel fluorescent nissl-like stain for neuroanatomy. Soc. Neurosci. Abstr. 14:547.

Rowe, J.S., and R.D. Beauchamp (1982) Visual responses of nucleus corticalis neurons in the perciform teleost, northern rock bass ( $A m$ bloplites rupestris rupestris) Brain Res. 236:205-209.

Sakamoto, N., and H. Ito (1982) Fiber connections of the corpus glomerulosum in a teleost, Navodon modestus. J. Comp. Neurol. 205:291-298.

Schnitzlein, H.N. (1962) The habenula and the dorsal thalamus of some teleosts. J, Comp. Neurol. 118:225-267.

Sheldon, R.E. (1912) The olfactory tracts and centers in teleosts. J. Comp Neurol. 22:177-339.

Striedter, G.F., and R.G. Northeutt (1986) Connections of the superficial pretectum and nucleus isthmi in the sunfish Lepomis cyanellus. Soc. Neurosci. Abstr. 12:103.

Striedter, G.F., and R.G. Northcutt (1989) Two distinct visual pathways through the superficial pretectum in a percomorph teleost. J. Comp Neurol. 283:342--354.

Swanson, L.W., W.M. Cowan, and E.G. Jones (1974) An autoradiographic study of the efferent connections of the ventral lateral geniculate nucleus in the albino rat and the cat. J. Comp. Neurol. 156:143-164.

Watts, A.G., L.W. Swanson, and G. Sanchez-Watts (1987) Efferent projections of the suprachiasmatic nucleus: I. Studies using anterograde transport of Phaseolus vulgaris leucoagglutinin in the rat. J. Comp. Neurol. 258:204-229.

Wullimann, M.F. (1985) Zum Gehirn von Rhinecanthus aculeatus (Linnaeus, 1758) (Balistidae, Tetraodontiformes, Teleostei). Basel: Inauguraldissertation.

Wullimann, M.F. (1988) The tertiary gustatory center in sunfishes is not nucleus glomerulosus. Neurosci. Lett. 86:6-10.

Wullimann, M.F., and D.L. Meyer (1989) Evolution of putative cholinergic visual pathways to the hypothalamus in teleost fishes. In N. Elsner and W. Singer (eds): Dynamics and Plasticity in Neuronal Systems. Stut tgart: Thieme, p. 330 (Abstract).

Wullimann, M.F., and D.L. Meyer (1990) Phylogeny of putative cholinergic pathways through the pretectum to the hypothalamus in teleost fishes. Brain Behav. Evol. 36:14-29.

Wullimann, M.F., and R.G. Northeutt (1986) Vision on the coral reef: Some visual circuits of humu humus (Balistidae). Soc. Neurosci. Abstr. 12:103.

Wullimann, M.F., and R.G. Northeutt (1989) Non-percomorph teleosts possess a homologue of nucleus glomerulosus. Soc. Neurosci. Abstr. 15:32

Wullimann, M.F., and R.G. Northcutt (1990) Connections of the hypothalamic inferior lobes in the teleost fish Osteoglossum bicirrhosum. Europ J. of Neurosci., Suppl. 3:188. 